\title{
Paisajes agrarios de Canarias ${ }^{1}$
}

\author{
José-León GARCÍA RODRÍGUEZ \\ Departamento de Geografía de la Universidad de La Laguna \\ jleongarcia@ull.es
}

Recibido: 30 de abril de 2012

Enviado a evaluar: 16 de julio de 2012

Aceptado: 12 de marzo de 2013

\begin{abstract}
RESUMEN
Las islas de pequeñas dimensiones han sido consideradas desde el pasado como excelentes laboratorios para el avance del conocimiento, a causa de su aislamiento, delimitación precisa, y extensión fácilmente abarcable para los investigadores. Sin embargo, en muchos casos resulta difícil aplicar categorías de análisis espacial concebidas para territorios más amplios, a la escala insular, debido a su modesta dimensión superficial, y en algunos casos también por su elevada fragmentación ocupacional. Esto es, por ejemplo, lo que ocurre con las propuestas de tipificación de los paisajes de la agricultura de las Islas Canarias, a causa de la limitación de la superficie cultivada, de la escasa dimensión de las parcelas y de la discontinuidad territorial de las explotaciones, las cuales han dificultado la clasificación de los paisajes vinculados a la actividad agraria, sobre unidades territoriales de suficiente dimensión espacial que merezcan tal denominación conceptual y no la de simples variaciones puntuales del mapa de cultivos.
\end{abstract}

Posiblemente por ello, la apreciación popular ha simplificado este problema estableciendo en las islas de relieve solo dos unidades de paisaje, vinculadas a la influencia climática, el Norte y el Sur, utilizando como criterios de diferenciación los rasgos de humedad o aridez característicos del clima de cada vertiente insular y los principales elementos identificadores de la ocupación humana de cada uno de dichos ámbitos geográficos, incluyendo entre estos últimos los cultivos y las formas de poblamiento. Y los primeros autores que han propuesto una clasificación académica más detallada que la anterior, lo han hecho también utilizando más los criterios agroclimáticos que los propiamente paisajísticos, que pretendemos aplicar en este trabajo, pues han incluido en su tipología la división altitudinal en pisos característica de la agricultura de las islas, con sus franjas de costa, medianías y cumbre. Pero el análisis crítico de las anteriores aportaciones y la revisión de los factores de tipificación de los paisajes agrarios de Canarias nos han llevado también a cuestionar el papel exclusivo de los cultivos como elementos definidores de las categorías de paisaje agrario del Archipiélago, teniendo en cuenta la limitada superficie cultivada, su elevada fragmentación parcelaria y la dispersión del mapa de cultivos de la región; y nos ha impulsado a considerar el papel de otros elementos como los materiales volcánicos usados como soporte agrario, que en muchos casos resultan más visibles que los propios cultivos, los sistemas agrarios existentes en las Islas, las técnicas de cultivo utilizadas en las diferentes áreas agrícolas, e incluso determinadas configuraciones culturales como la conocida franja de Las Medianías a la hora de formalizar la propuesta operativa de paisajes agrarios que presentamos en este trabajo.

\footnotetext{
${ }^{1}$ Este artículo es el resultado parcial de la investigación llevada a cabo por el autor dentro del proyecto CSO2009-12225-C05-03, denominado Las unidades básicas de paisaje agrario de España: identificación, delimitación, caracterización y va loración. La España mediterránea cálida, insular y va lle del Ebro, financiado inicialmente por el Ministerio de Ciencia e Innovación.
} 
Palabras clave: Escala insular, clasificación de paisajes agrarios, mapa de cultivos, sistemas agrarios, técnicas de cultivos, materiales de soporte agrícola.

\title{
Canary islands agricultural landscapes
}

\begin{abstract}
The small islands have been considered from the past as excellent laboratories for the advancement of knowledge, because of their isolation, precise delineation and easily affordable by researchers. However, in many cases it is difficult apply categories of spatial analysis designed for wider areas to modest dimension of insular scale and, in some cases, showing high fragmentation occupational. That is, for example, what happens to the proposed classification of the agricultural landscapes of the Canary Islands, because of the limitation of the cultivated area, the small size of plots and territorial discontinuity of farms. These factors have hindered the classification of landscapes related to agricultural activity on territorial units of sufficient size, and not only simple points in map of crops.
\end{abstract}

Possibly for this reason, the popular appreciation has simplified this problem by establishing on raised islands only two landscape units, linked to climatic influence, the North and South. The criteria of differentiation used has been the features characteristic of dampness or dryness of the climate of each side and identifying elements of human occupation of each of these geographic areas, including crops and forms of settlement. The first authors who have proposed a formal classification more in detail, have used more agro climatic criteria than the actual landscape, since these authors have included in their division a typology based on altitudinal floors feature of agriculture in the islands, with its stretch of coastline, medium and summit. But the critical analysis of previous researches and review of the factors for defining the agricultural landscapes of the Canary Islands have also led us to question the exclusive role of culture as defining element of the categories of agricultural landscape of the archipelago, taking into account the limited acreage, the high fragmentation of holdings and the dispersion map of crops in the region. The above factors has led us to consider the role of other elements such as volcanic materials used to support agriculture, which in many cases are even more visible that crops, farming systems existing in the Islands, the cultivation techniques used in various agricultural areas, and even certain cultural configurations as the known fringe of Las Medianías, to formalize the operative proposal of agricultural landscapes presented in this work.

Key words: Scale insular, agrarian landscape classification, map of crops, farming systems, farming techniques, agricultural support materials.

\section{INTRODUCCIÓN}

La apreciación popular ha distinguido tradicionalmente en las islas de mayor relieve del Archipiélago canario dos amplias zonas diferenciadas por su imagen natural y humana, el Norte y el Sur, utilizando como criterios de diferenciación las características climáticas específicas de cada vertiente, los rasgos paisajísticos derivados de las mismas y los principales elementos producidos por el uso y la cultura en cada uno de dichos ámbitos insulares. Esta clasificación territorial contrapone básicamente humedad y aridez, y simplifica los puntos cardinales en relación con sus posibilidades de explotación para el sistema agrario tradicional. Identifica el Norte con la zona húmeda de barlovento, afectada por la corriente del alisio, que sopla del noreste, genera abundante vegetación en las áreas más favorecidas; y ha posibilitado un mayor aprovechamiento agrario, y por tanto, una ocupación humana más intensa y continua del 
territorio, especialmente en el denominado ámbito de Las Medianías. Por el contrario, equipara el Sur con la vertiente de sotavento, que queda a cubierto de dicho flujo o está condicionada por los fenómenos orográficos de aceleración del alisio, y por lo tanto, resulta más árida y soleada, y en general, posee menos vegetación que la anterior, y asimismo presenta más dificultadas para el desarrollo de la agricultura de secano, especialmente por debajo de la curva de nivel de los $400 \mathrm{~m}$ de altitud, por lo que ha estado mucho menos poblada en el pasado.

Ambas fachadas insulares, separadas por el relieve de las montañas, han sido históricamente dos mundos bastante diferentes en el modelo de desarrollo tradicional, por sus acusados contrastes en la distribución de los cultivos y de la población, a favor de la fachada septentrional, al parecer desde la misma etapa de la Colonización de las Islas. Estas diferencias socioeconómicas y demográficas se han ido suavizando en las últimas décadas, aunque subsisten en la actualidad. Se han mitigado, primeramente con la extensión de la agricultura comercial de regadío, en la zona baja, y posteriormente, con el desarrollo turístico. Ambas actividades han aprovechado las mejores condiciones térmicas y de insolación de la franja costera de la fachada meridional para la instalación de las explotaciones agrarias y de las infraestructuras alojativas del turismo de masas, que han acabado compitiendo por el mismo espacio y los recursos hídricos en algunos lugares de Tenerife y Gran Canaria.

Este esquema paisajístico y territorial coincide, a grandes rasgos, con el que presenta la isla de Tenerife, la cual muestra una distribución del relieve orientado, en general, de noreste a suroeste; aunque, en realidad, y a partir del macizo de Anaga, el edificio insular forma un triángulo en torno a la caldera de Las Cañadas y al pico del Teide y da lugar a tres fachadas o laderas de mar a cumbre; una septentrional, afectada de lleno por el flujo húmedo del alisio, que acaba en el macizo de Teno; otra meridional situada a sotavento de la primera, en la que el alisio se acelera y deseca, la cual termina en la árida punta de Rasca; y una tercera ubicada al oeste de la isla, entre las dos anteriores, que queda a cubierto de dicho flujo. Este croquis ambiental con dos vertientes más secas, e incluso áridas en algunos ámbitos, que representan el Sur para la percepción popular; y una vertiente más húmeda, aunque con variaciones de este a oeste, que simboliza el Norte, ha sido utilizado como modelo explicativo de la ocupación del territorio y de los paisajes insulares para el conjunto del Archipiélago, incluyendo en el análisis la existencia de tres franjas altitudinales diferenciadas, la costa, las medianías y la cumbre, debido el peso académico y cultural de de la isla de Tenerife en la producción inicial del conocimiento geográfico regional.

El destacado relieve de la mayoría de las Islas Canarias ha dado lugar a la existencia de distintas franjas altitudinales en la ocupación del territorio, diferenciadas también desde el pasado por la percepción de la población, que se basan en la presencia de factores naturales y humanos que han posibilitado una notable diversidad de aprovechamientos y han generado una cierta variedad de paisajes rurales desde la zona baja hasta la cima de las montañas, en el modelo de desarrollo tradicional, pero que han llegado hasta nosotros, a pesar de los importantes cambios socioeconómicos y territoriales que se han producido en el último medio siglo. 
Dicha zonificación del espacio insular, consolidada en numerosos trabajos científicos realizados primeramente por ingenieros agrónomos y después por geógrafos, y ampliamente difundida en obras de notable tirada editorial y de uso docente en la región, a partir de los años ochenta, como la Geografía de Canarias (1984-1992) y el Atlas Interinsular de Canarias (1990), pone de manifiesto la importancia de la orografía y la orientación en la determinación de áreas diferenciadas desde el punto de vista funcional o paisajístico en las islas de relieve afectadas por los alisios, a pesar de la modesta extensión superficial de las mismas.

Un reflejo de la notable diversidad de ámbitos paisajísticos, ecológicos, botánicos, faunísticos y geológicos existentes en Canarias es el elevado número de espacios naturales incluidos bajo alguna figura de protección ambiental, inicialmente al amparo de la Ley 12/1994 de Espacios Naturales de Canarias y posteriormente del Decreto Legislativo 1/ de 8 de mayo, por el que se aprueba el Texto Refundido de las Leyes de Ordenación del Territorio de Canarias y de Espacios Naturales de Canarias. Dichos espacios protegidos para su conservación son 146 en todo el Archipiélago, incluyendo los cuatro parques nacionales, y suponen nada menos que el 40,5 por ciento de la superficie regional.

Específicamente para hacer referencia a los diferentes ámbitos altitudinales de uso y aprovechamiento, se han acuñado en el lenguaje ordinario de las Islas y en el vocabulario académico los conocidos términos de «costa», «medianías» y «cumbre», aplicados, respectivamente, a la zona baja, de características térmicas subtropicales, pero de escasas precipitaciones, e incluso de aridez, en muchos ámbitos meridionales de las islas de Tenerife y Gran Canaria; a la zona intermedia, altitudinalmente situada sobre la anterior, pero mucho más húmeda que esta, por el efecto combinado de los alisios y de la altitud, especialmente en la vertiente septentrional de las islas; y finalmente, la zona alta o de cumbre, localizada en la franja superior de la isla, en el ámbito del monte y del matorral de montaña media, con aprovechamientos fundamentalmente forestales y pastoriles.

Pero el cambio de modelo económico y espacial que se ha producido en Canarias de la agricultura al turismo, o el ajuste territorial posterior a los años sesenta, ha ocasionado también una destacada transformación en el limitado espacio rural de las Islas, tanto en la zona baja, donde se ha producido un notable avance en la tecnificación de los cultivos de plátanos, hortalizas, plantas ornamentales y flores, y un espectacular proceso de urbanización; como en la franja altitudinal de Las Medianías, en la que ha tenido lugar un masivo abandono de los cultivos tradicionales de secano (cereales, leguminosas, papas y hortalizas), la mayoría dedicados al consumo interior, y un notable avance de la edificación, sobre los terrenos dejados por los cultivos en las áreas de influencia de los principales núcleos de población y enclaves turísticos.

En relación con la aplicación del mencionado modelo explicativo de la ocupación del territorio y de los paisajes insulares de Tenerife a las restantes islas, es necesario destacar que tanto la dirección de los vientos alisios como el reparto local del relieve producen algunas «distorsiones» en la distribución geográfica de dichas zonas agroclimáticas, como sucede por ejemplo, en Gran Canaria, cuya orografía es radial, su elevación máxima se sitúa en el centro del edificio insular, y la apreciación popular 
incluye en la zona meridional de la isla a toda la comarca oriental de la misma, que está situada al sur de Las Palmas, probablemente a causa de su posición relativa con respecto a la ciudad y de su manifiesta aridez, visible incluso en los desplazamientos cotidianos de los viajeros a lo largo de la autopista del Sur.

Algo similar ocurre en La Palma, cuyo relieve se extiende de norte a sur, a partir de la orografía radial de la porción septentrional de la misma, la denominada Paleopalma por su mayor antigüedad geológica, lo que da lugar a la división de la isla en dos mitades, una oriental, afectada por el flujo húmedo del alisio, aunque este se acelera y deseca en dirección meridional, y esto se refleja en la vegetación y en los aprovechamientos humanos; y otra occidental, a resguardo habitualmente de dicho flujo, pero que reciben el apelativo popular de Norte y Sur, respectivamente, a pesar de sus ubicaciones geográficas concretas al este y al oeste del edificio insular, separadas por el relieve de las cumbres Nueva y Vieja.

Pero la tarea de tipificación académica de los paisajes de la agricultura de Canarias se ve dificultada, en primer lugar, por la escasa superficie cultivada de la región, que apenas alcanza las 47.000 hectáreas, según el vigente y algo desfasado Mapa de Cultivos de Canarias, lo que supone poco más del 6 por ciento de la misma; y también por la dispersión espacial y la diversidad local de los cultivos, derivada de factores climáticos favorables a la pluralidad agrícola; por la escasa dimensión de las parcelas, debida a la inclinación del terrazgo y a la fragmentación histórica de la propiedad; y finalmente, por la discontinuidad territorial de las explotaciones, que complican la clasificación específica de los diferentes tipos de paisajes, vinculados a la actividad agraria y a la percepción de rasgos homogéneos definidores por parte de los observadores, sobre unidades territoriales de suficiente dimensión espacial que las haga acreedoras de tal denominación conceptual y no de simples variantes locales del mapa de cultivos o de los sistemas de cultivo, como ocurre con algunas de las tipologías realizadas por los mencionados autores de referencia.

En este contexto de dispersión y diversidad agraria y baja densidad del espacio cultivado, el paisaje vinculado a las prácticas agrícolas más evidente en muchos lugares de las islas es precisamente el del abandono agrario, con sus parcelas vacías y sus paredes caídas, que van siendo invadidas por el matorral más oportunista o el bosque más colonizador, y ocupan ya más de 93.000 hectáreas, lo que supone el 12,5 por ciento de la superficie del Archipiélago en los diferentes pisos de ocupación agraria, según el registro cartográfico de la citada fuente, aunque a efectos estadísticos oficiales se considera este abandono como un largo barbecho, carente de labores, y a la espera de ser cultivado en algún momento, si no llega antes el temido efecto invasor de la autoconstrucción o la recalificación del suelo para uso urbano. 
Figura 1. Abandono agrario en Haría, Lanzarote.

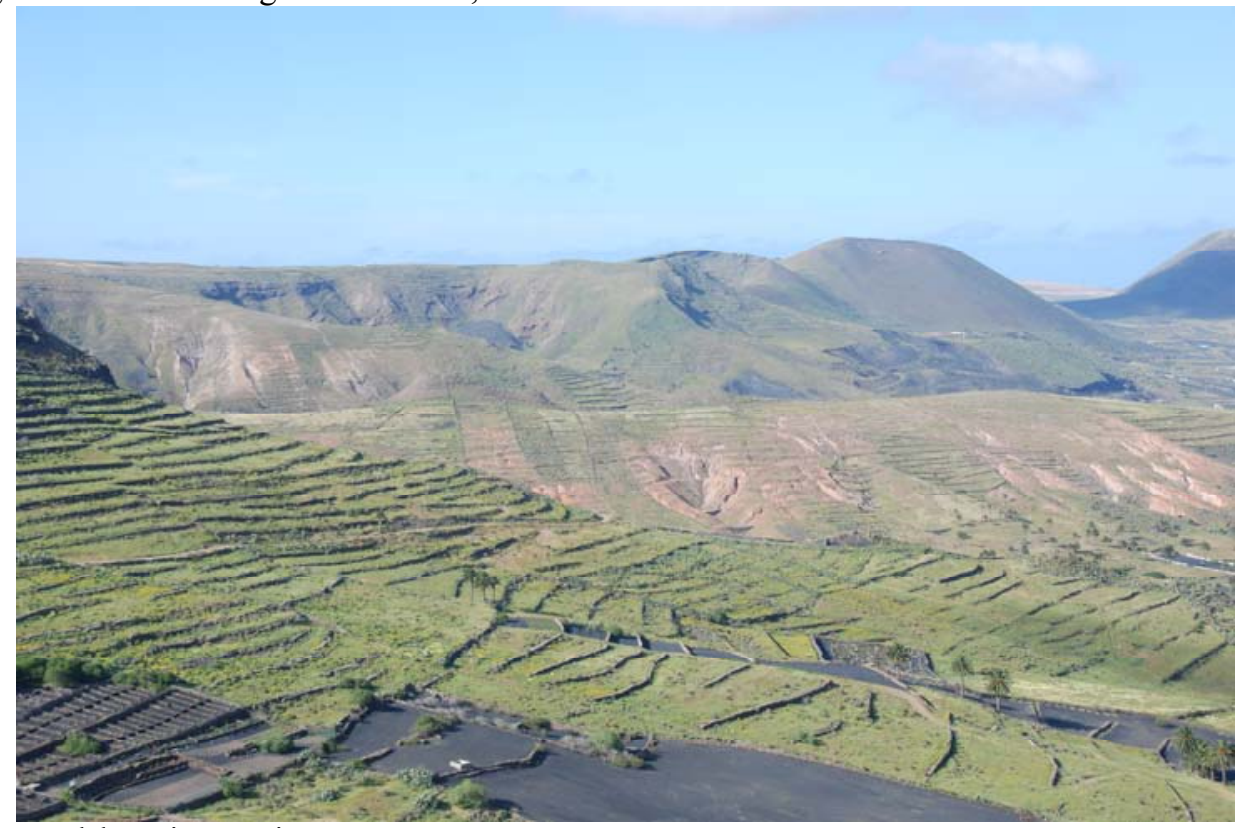

Fuente: Elaboración propia.

La tipificación paisajística del espacio cultivado en Canarias ha sido abordada con anterioridad a este trabajo casi exclusivamente por dos autores, Álvarez Alonso (1993) y Martín Martín (2000), siguiendo metodologías apenas explicitadas y aparentemente contrapuestas, a partir en algunos casos de los datos imprecisos de la memoria y de planteamientos más agrarios que paisajísticos, aunque carentes en ambos casos de basamento cartográfico alguno para ubicar geográficamente sus categorías. El primero de los autores señalados establece una clasificación territorial de los paisajes con pocas unidades, basada en los conocidos pisos agroclimáticos de Canarias, en los rasgos de aridez y humedad de los cultivos, e incluso en la finalidad familiar o comercial de las explotaciones. En cambio, Víctor Martín propone una tipificación más amplia de los paisajes de la agricultura de las Islas, sustentada no solo en la diversidad de los cultivos y de las parcelas, sino también en los factores naturales y humanos de la agricultura, que se aproxima más en sus unidades a los sistemas de cultivo existentes en Canarias que a los paisajes de la agricultura propiamente dichos.

\section{LAS PRIMERAS PROPUESTAS DE TIPIFICACIÓN DE LOS PAISAJES AGRARIOS DE CANARIAS}

El citado profesor Álvarez Alonso establece en su clasificación de los paisajes de la agricultura de Canarias un primer gran grupo denominado «los paisajes agrarios de las zonas áridas», que puede englobarse según sus propios términos bajo el epígrafe de «agricultura de secano de los medios áridos», que incluye los cultivos sobre los 
piroclastos volcánicos y arenas marinas en Lanzarote, y sobre las gavias y nateros en Fuerteventura, aunque ambos podían ser regados de manera ocasional y por procedimientos rudimentarios, según dicho autor, en función de la intensidad de la sequía del año meteorológico; y también los cultivos de papas sobre jable o pumitas blancas del sur de Tenerife, algo más irrigados que los anteriores, incluso de modo regular, mediante sistemas economizadores de agua; y asimismo los viñedos de secano del sur de La Palma y del norte de El Hierro, cultivados sobre piroclastos negros de origen reciente.

Figura 2. Cultivos de batatas irrigados sobre enarenados, en San Bartolomé, Lanzarote.

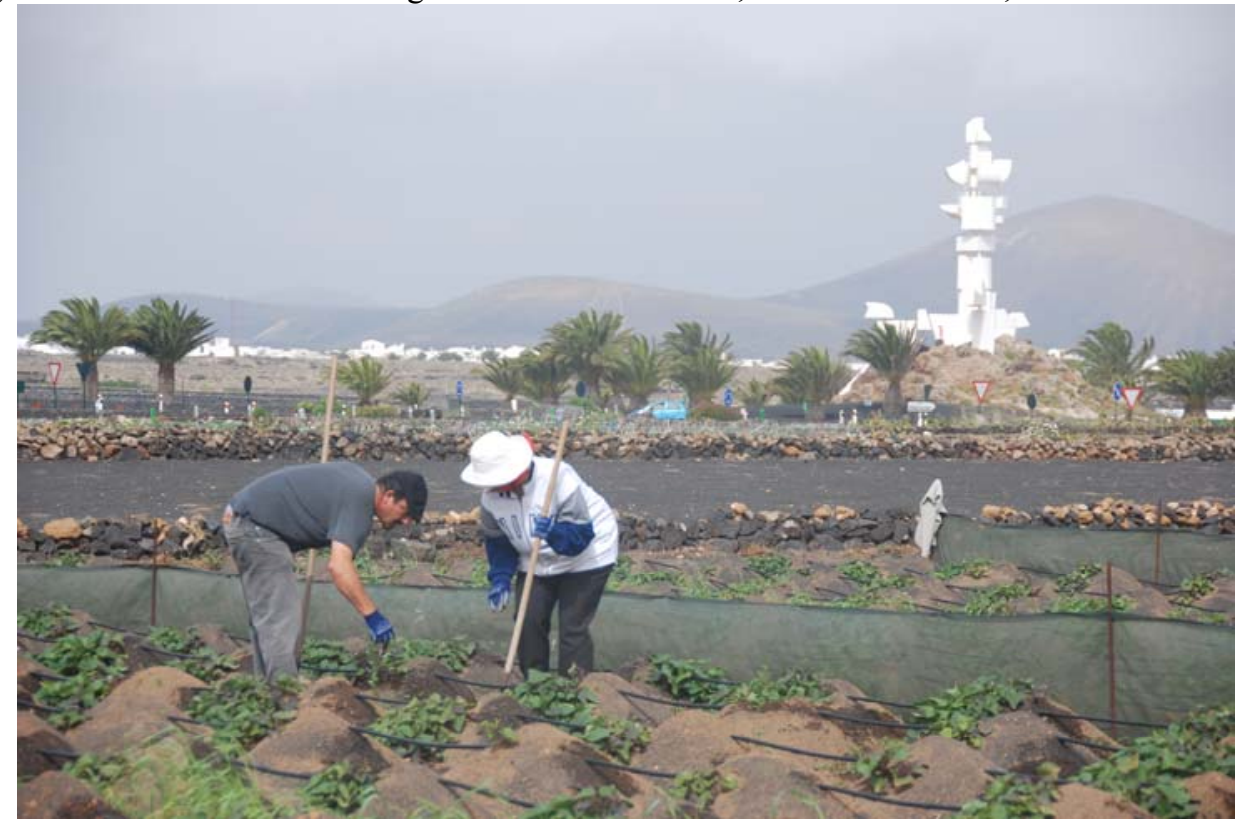

Fuente: Elaboración propia.

Pero este grupo contiene, en realidad, diferentes tipos de paisajes agrarios, de secano y regadío: el de los cereales y hortalizas de secano sobre enarenados naturales y artificiales de Lanzarote, que puede ser ocasionalmente irrigado; el de cereales, maíz y papas de secano sembrados en las gavias y nateros de Fuerteventura, que en la práctica casi ha desaparecido en la actualidad; el de viña de secano sobre escorias y enarenados volcánicos naturales de La Palma y El Hierro; y el de las papas de regadío sobre enarenados artificiales de piroclastos blancos del sur de Tenerife.

A todos ellos, salvo al paisaje de gavias de Fuerteventura, lo que les une realmente es una técnica agrícola, el enarenado, que es natural y de origen marino en la zona del Jable, en Lanzarote; también es natural pero de origen volcánico en los viñedos del sur de La Palma y del norte de El Hierro, e igualmente formado por el vulcanismo reciente en el llamativo paisaje vitícola de La Geria y en otros ámbitos de Lanzarote, 
que Álvarez Alonso no incluyó de manera explícita en este grupo ni en ningún otro; y es artificial en algunos enclaves de Fuerteventura y en la mayor parte de Lanzarote, donde se cultivan en la actualidad viñedos y hortalizas en huertas acondicionadas con técnicas cercanas a la jardinería, que progresivamente han ido adquiriendo instalaciones de riego localizado en el segundo caso para mejorar sus rendimientos; y es igualmente artificial en las parcelas cubiertas de jable o piroclastos blancos en el sur de Tenerife, dedicadas especialmente al cultivo de papas en regadío con destino a la exportación hasta finales de los años setenta, y posteriormente también a otras hortalizas y a la vid para el mercado insular.

La justificación de que el nexo de unión entre las anteriores unidades espaciales, establecidas por la agricultura, es el sistema de cultivo y no el tipo de paisaje agrario de las zonas áridas nos la ofrece el propio autor al distinguir en Lanzarote tres «formas de cultivar la lava», como consecuencia de las condiciones extremas de aridez de la isla, que son los cultivos en huecos o zanjas, los arenados y los jables. Con respecto a los primeros, el autor tinerfeño señala que «en la zona central de la isla, en las inmediaciones de La Geria y en algunos otros lugares, se plantan higueras, viñas y otros frutales en los agujeros que dejan las coladas de lava o en zanjas hechas por el propio campesino, rompiendo aquellas. El efecto que se consigue con esta técnica de cultivo es triple: alcanzar el suelo vegetal, cubierto por el material lávico, aprovechar la humedad edáfica retenida al quedar al resguardo de los rayos solares y proteger los cultivos del fuerte viento» (Álvarez Alonso, 1993: 321).

El segundo gran grupo que presenta la tipología de los paisajes de la agricultura de este autor prematuramente desaparecido es «el paisaje agrario de los medios subhúmedos», denominado también como «el policultivo de secano de las medianías», que se localiza entre los 300 y los 1.000 metros de altitud en las vertientes de barlovento y algo más arriba en las del sur de todas las Islas (excepción hecha de Lanzarote y Fuerteventura por su menor altitud), y constituye en su conjunto un ecosistema, caracterizado por una cierta diversidad, tanto biológica como cultural (Álvarez Alonso, 1993: 322), que ha ido disminuyendo con el retroceso de la agricultura y el número de cultivos.

El rasgo climático característico del conjunto de las tierras de Las Medianías es la «humedad» en sentido agroclimático, según el autor de esta propuesta, lo que ha permitido el desarrollo de la agricultura de secano, constituida por los cultivos de cereales, papas y frutales, a los que hay que añadir las hortalizas, las leguminosas y las forrajeras, cada uno con sus respectivas variedades. El paisaje agrario de esta franja altitudinal alcanzó su máxima extensión superficial en la década de los cincuenta del pasado siglo, que es quizás una de las etapas de la historia económica del Archipiélago de mayor presión demográfica sobre los recursos agrarios (Álvarez Alonso, 1993: 323), lo que provocó un intenso proceso emigratorio que llevó al exterior a muchos miles de canarios.

El ámbito territorial del mencionado policultivo de secano se extendió en el Archipiélago por los valles o vegas del norte de Gran Canaria, desde San Mateo hasta Artenara; por las bandas del norte de Tenerife, desde Anaga hasta Teno; por la mayor parte de las tierras de El Hierro y de La Gomera (en donde los cultivos escalaron ladera arriba hasta lugares inverosímiles, en Valle Gran Rey o Vallehermoso); y por 
las laderas septentrionales, centrales y meridionales de La Palma. Pero desde los años cincuenta hasta la actualidad la situación ha cambiado sensiblemente. Se ha producido, en primer lugar, un abandono del 65,1 por ciento de las tierras cultivadas con anterioridad, según el Mapa de Cultivos de Canarias (2003-2008). En segundo lugar, se ha procedido a una selección rigurosa de las plantas en aquellas zonas que aún se cultivan: frutales y algunas hortalizas en Gran Canaria, en relación con el mercado de Las Palmas, viñedo y papas del país en Tenerife. Los cereales y las legumbres casi han desaparecido. Por último, se ha impuesto el sistema de agricultura a tiempo parcial (Álvarez Alonso, 1993: 324).

El tercero y último de los grandes tipos de paisajes propuesto por el primer autor de referencia es el de «los paisajes agrarios de las franjas litorales», que están situados por debajo de la cota de los 300 metros de altitud en el norte y algo más arriba en el sur, donde se ubican, entre otros, los cultivos termófilos de exportación. Se trata, según Álvarez Alonso, de una agricultura de regadío, fuertemente capitalizada, asentada sobre un terrazgo construido en parte de manera artificial y dedicado a la producción intensiva de productos alimenticios y plantas ornamentales, como el plátano, el tomate, algunas hortalizas y flores. La superficie cultivada ha sufrido una sensible reducción en las últimas décadas, pero ha ido acompañada de una importante intensificación, que ha permitido elevar los rendimientos y aumentar la productividad (Álvarez Alonso, 1993: 324).

Una tipología más compleja, y también más reciente que la anterior, sobre los paisajes de la agricultura y de la ganadería de Canarias, es la debida a Martín Martín (2000), con 9 grandes grupos que se concretan en 15 categorías territoriales, repartidas de forma desigual por todas las Islas. La distribución la realiza el citado autor en función de la importancia agropecuaria de cada una de estas, lo que resulta una novedad, al incluir las escasas y dispersas explotaciones ganaderas de la región en una categorización espacial. Las pautas de clasificación de las diferentes unidades que establece son variadas, pero aparentemente tienen más que ver con los elementos de análisis de la agricultura que con los criterios de tipificación del paisaje, puesto que utiliza como parámetros la naturaleza del suelo cultivado, la localización altitudinal de los cultivos, las técnicas de construcción del terrazgo agrícola, la forma y el tamaño de las parcelas, el régimen hídrico, el sistema de cultivo, el destino de la producción agraria y la estructura de la propiedad de la tierra, aunque en ningún caso hace uso de la cartografía para precisar la ubicación geográfica de las distintas coberturas de paisaje. La carencia de esta importante herramienta en la determinación espacial de los paisajes de la agricultura induce a este autor a justificar la existencia insular de sus categorías analíticas mediante la presencia puntual de unidades de paisaje que cumplen supuestamente los criterios definidos para las mismas, aunque por su limitada dimensión superficial y su caracterización agronómica dichas unidades se acerquen más a las variaciones locales del mapa de cultivos que al concepto de unidad canónica de una categoría específica de paisaje.

La combinación de los anteriores parámetros en las diferentes áreas agrícolas del Archipiélago lleva a Martín Martín a lo que considera en su trabajo de referencia 
como una primera aproximación a los paisajes agrarios de las Islas, con los siguientes tipos generales: 1) el paisaje de medianías; 2) el paisaje de gavias, nateros y bebederos; 3) el paisaje en litosuelos; 4) el paisaje de enarenado con substratos; 5) el paisaje de las arenas marinas; 6) el paisaje en terrazas; 7) el paisaje tradicional del plátano; 8) el paisaje de invernaderos; y 9) el paisaje ganadero. Por ello el propio autor señala que la anterior relación resulta incompleta, pues no contiene todos los tipos de paisajes agrarios existentes en la región, según su criterio, ya que no están contemplados, por ejemplo, «los cultivo de tuneras para la cría de cochinilla» en Lanzarote o «las viñas en cepas» de Vilaflor en Tenerife; ni tampoco se incluyen los paisajes agrarios desaparecidos, como «los cultivos de cereales» en las áreas costeras, «el cultivo extensivo de tomates» o «la ganadería semitrashumante de costa a cumbre» en Tenerife; y por otra parte, algunos de los paisajes que contiene el listado es posible subdividirlos, pues en el paisaje de medianías del norte de Tenerife existen claras diferencias entre los llanos de Los Rodeos, la comarca de Acentejo o las medianías de Icod (Martín Martín, 2000: 99).

Sin embargo, algunas de las categorías de este importante intento de tipificación general de los paisajes agrarios de Canarias resultan cuando menos discutibles, e incluso en algunos casos pueden llegar a ser claramente arbitrarias, a causa de los criterios utilizados en su determinación, y otras carecen de referente geográfico en la agricultura actual de las islas, puesto que miran más hacia el pasado de la memoria que al presente, como se tendrá ocasión de demostrar en las líneas que siguen a continuación. Este es, por ejemplo, el caso del primero de los arquetipos paisajísticos incluidos en la propuesta de Martín Martín, el del emblemático «paisaje de medianías», que ubica en la franja agrícola situada entre los 400 y los $800 \mathrm{~m}$ de altitud de las fachadas de barlovento de las islas de Tenerife y Gran Canaria (y no en las restantes islas occidentales ni en sus fachadas de sotavento de las mismas); y vincula visualmente esta franja altitudinal al cultivo de cereal, millo, leguminosas, variedades locales de papas o barbecho; y también a las asociaciones de cultivos en una misma parcela (viña-cereal, viña-millo, viña-papas, viña- millo-papas, viña-frutales, millo-papas, legumbres-millo, frutales-papas, cereal-millo-papas, etc.). La explicación de tales sistemas radica, según dicho autor, en el extremado minifundismo existente y en los específicos regímenes de tenencia de la tierra, que obligaban al campesino a un aprovechamiento intensivo del terrazgo desde el punto de vista espacial y temporal, con la finalidad de asegurarse su subsistencia (Martín Martín, 2000:99). Pero esta modalidad de cultivo de secano ha desaparecido casi en su totalidad, desde hace varias décadas, y una parte del terrazgo abandonado por los cereales y las leguminosas ha sido ocupado por nuevas edificaciones destinadas a uso residencial, como consecuencia del intenso proceso de urbanización de Las Medianías húmedas, y por el cultivo del viñedo, hechos que no menciona Martín Martín en su análisis, y que sin lugar a dudas han modificado de manera significativa el paisaje de este ámbito insular. Por otra parte, la extensión del viñedo se ha visto impulsado por la revalorización del vino local y el establecimiento de la denominación de origen Tacoronte Acentejo, en el caso de la isla de Tenerife. 
Algo parecido puede decirse también con respecto a la pertinencia de la segunda de las categorías de paisajes de la agricultura propuesta por el mencionado autor para la isla de Fuerteventura (y no para la isla de Lanzarote, donde también se registró), la relativa al «paisaje de gavias, nateros y bebederos». Pues este original sistema de aprovechamiento de las aguas de lluvia y de los lodos fertilizantes procedentes de las escorrentías en las zonas áridas, con el objetivo de producir cereales y papas o mantener algunos árboles frutales, en el interior de las parcelas cercadas, ha dejado de utilizarse desde hace varias décadas ante la imprevisibilidad de las precipitaciones, la persistencia de las sequías, y sobre todo como consecuencia de la mejora de la economía insular y del consiguiente aumento del nivel de vida de la población, propiciada por el desarrollo del turismo, posterior a los años setenta del siglo pasado. Este último factor ha posibilitado también que la escasa agricultura que aún subsiste en Fuerteventura sea de regadío, utilizando sobre todo agua desalada, de la red insular de abastecimiento público, ya que el agua de los pequeños pozos artesanales que se mantienen todavía activos es escasa y salobre. Sin embargo, las instituciones públicas de Fuerteventura, y algunos empresarios agrícolas, se han encargado de mantener casi operativo el tradicional sistema de gavias y nateros en muchas áreas de la isla, sobre todo con la finalidad medioambiental de facilitar la infiltración de las aguas en el subsuelo para recargar los modestos acuíferos insulares y luchar de paso contra la erosión y la destrucción de las antigua explotaciones, lo que sin duda ha contribuido al mantenimiento de este original paisaje de parcelas cercadas por caballones de tierra compactada, pero prácticamente vacías de cultivos en su totalidad. Ambos objetivos ambientales se han unido a los programas de mejora de la vegetación autóctona y de preservación general de los ecosistemas áridos, lo que ha supuesto la inclusión de la isla de Fuerteventura entre las reservas mundiales de la biosfera de la UNESCO en 2009.

En cambio, las tres categorías siguientes de la clasificación de Martín Martín, «el paisaje en litosuelos», «el paisaje de enarenado con substratos» y «el paisaje de las arenas marinas» se pueden unificar en una sola tipología, pues son en realidad diferentes modalidades de paisaje o variantes locales de un paisaje agrario único, que contiene diferentes cultivos, viñedos, algunas hortalizas y leguminosas o papas, según la orientación de las áreas de aprovechamiento y las islas en las que se localiza, y que comparte una técnica agraria común que le da una notable homogeneidad, como es el enarenado, cuyos materiales de origen volcánico o marino utilizados tradicionalmente por los agricultores como soporte o entorno de los cultivos, constituyen el principal elemento definidor de esta tipología de paisaje agrario por su amplio marco de plantación o de siembra, que deja al descubierto la mayor parte de esta original modalidad de «suelo» agrario, de color gris, negro, blanco o amarillo, conformado en algunos casos por escorias volcánicas más o menos fragmentadas, y en otros por lapillis relativamente recientes, o arenas marinas arrastradas por el viento isla adentro, desde la playa de Famara hasta alcanzar la costa de sotavento, en el caso de Lanzarote, dando lugar a la zona del Jable. Las unidades canónicas de paisaje agrario elegidas por el citado autor como ejemplos representativos de las anteriores categorías paisajísticas, como son los paisajes de breñas del Hoyo de Mazo, en La Palma; los 
paisajes de piroclastos de La Geria, en Lanzarote; y los paisajes de jable de origen volcánico o marino del sur de Tenerife o de la mayor parte de Lanzarote, comparten no solo un soporte unificador desde el punto de vista agrícola y desde la perspectiva visual, sino también una moderada lista de cultivos, que no cubren más que una parte del mismo. Por ello tiene poco sentido analítico la anterior división tripartita de una misma realidad paisajística.

Figura 3. Cultivo de viña sobre jable en Arico, Tenerife.

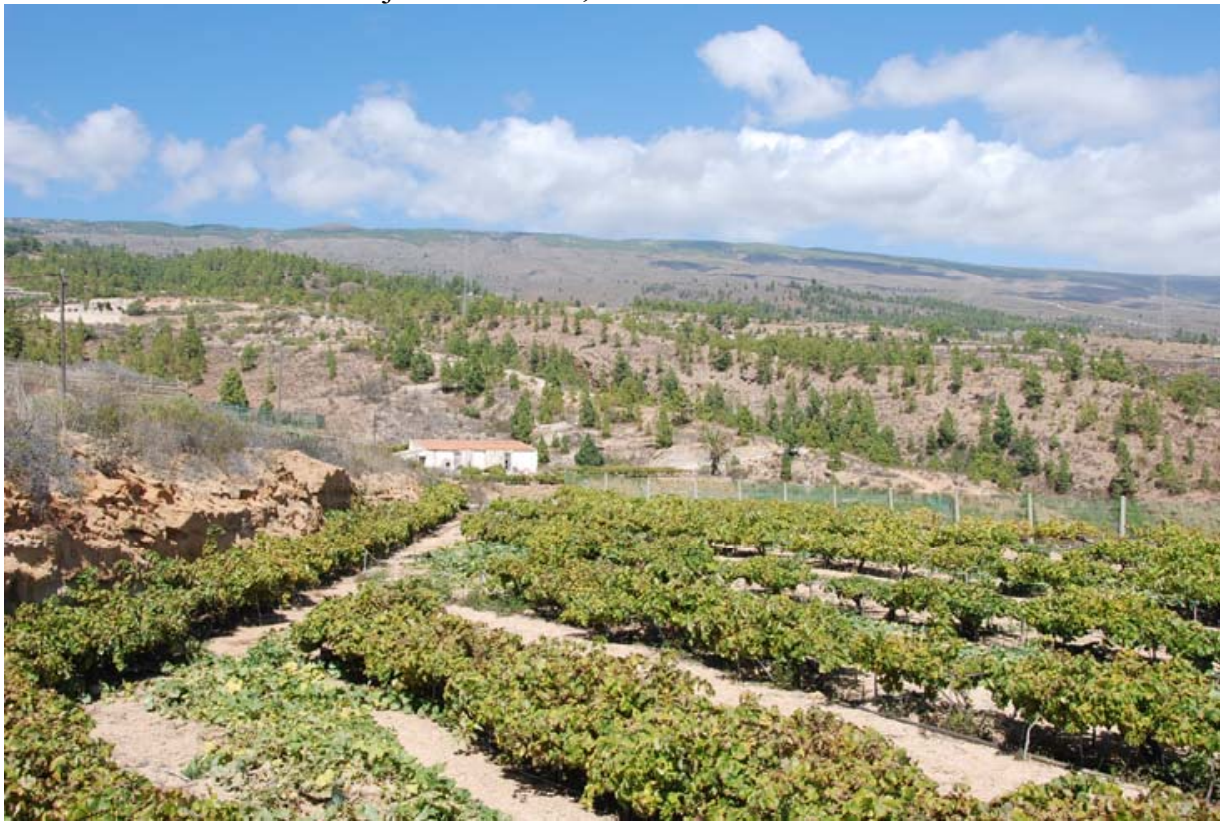

Fuente: Elaboración propia.

La construcción de bancales destinados al asentamiento de los cultivos es una exigencia de los terrenos que superan determinado grado de pendiente para evitar la perdida de suelo y facilitar las labores agrícolas, como ocurre en una buena parte del Archipiélago canario, y especialmente en determinados barrancos de La Gomera, donde esta práctica agrícola alcanzó una gran intensidad en los años cuarenta y cincuenta del siglo XX, fruto de la fuerte presión demográfica sobre el pequeño terrazgo insular y de la elevada fragmentación de la propiedad de la tierra. Pero las terrazas son un sistema de cultivo universal, que puede dar lugar a diferentes tipos de paisajes agrarios, según los cultivos que alberguen las parcelas y la presencia de otros rasgos diferenciadores de la morfología o de la cultura agraria. En el caso del valle de Hermigua, situado al norte de la citada isla, y que Martín Martín utiliza como ejemplo canónico de lo que considera un tipo de paisaje agrario («el paisaje en terrazas»), la necesidad de nivelar el terreno para facilitar el riego de las parcelas y los mayores rendimientos agrícolas del regadío sobre el secano, impulsaron la construcción de 
miles de pequeñas terrazas en un contexto socioeconómico de autarquía y elevado subempleo. Estas parcelas «no superan $\operatorname{los} 250 \mathrm{~m}^{2}$ de superficie media», según Martín Martín (2000:105), escalan la ladera izquierda del barranco y conforman un singular «paisaje tradicional de la platanera», que en parte ha sido abandonado a causa de la pérdida de rentabilidad de sus minúsculas explotaciones.

La platanera es el único cultivo de Canarias que por su destacada extensión superficial, especialmente en las islas de Tenerife, Las Palma y Gran Canaria, y por su importante continuidad espacial en la franja agroclimática de costa, constituye un verdadero paisaje agrario específico en las «comarcas» del valle de La Orotava, Las Galletas, costa de Guía de Isora, valle de Aridane, costa noreste de La Palma, y en menor medida, en el valle del Golfo, en El Hierro, y como se ha mencionado con anterioridad, en el valle de Hermigua, en La Gomera. Las plantaciones de plátanos se han situado generalmente en los terrenos más llanos de las Islas, localizados por debajo de los $300 \mathrm{~m}$ de altitud, y también en los mejores suelos que disponían de agua para el riego desde la etapa de la Conquista del Archipiélago, aunque en algunos lugares resguardados de los flujos frescos del noreste, suben por encima de esta cota y escalan incluso empinadas laderas. El profesor Víctor Martín (2000:105-106) ha seleccionado en su epígrafe relativo al «paisaje agrario tradicional del plátano» dos ejemplos supuestamente representativos del mismo, el de la «vega de Gáldar», en el noroeste de Gran Canaria; y el de «Los Llanos de Tazacorte» (sic), mezclando en este último caso en su denominación los nombres de los dos términos plataneros del valle de Aridane y cambiando de lugar en su descripción los rasgos distintivos del espacio cultivado en cada uno de estos municipios palmeros. Sin embargo, apenas establece diferencias entre los paisajes plataneros de Gran Canaria y La Palma, si exceptuamos las referencias a la concentración del poblamiento de Tazacorte en las áreas de menor valor agronómico, hecho que también podríamos hacer extensivo a la vega grancanaria, al igual que la presencia de vías de servidumbre para llegar hasta las parcelas y de muros cortavientos en torno a los bancales para proteger los cultivos. Por otra parte, también se puede constatar en ambos enclaves plataneros la importante extensión actual del sistema de cultivo bajo plástico, que Martín Martín no menciona, y ha supuesto un importante impacto en el paisaje agrario de estas y de otras áreas plataneras de la región, donde cubre más de la tercera parte de las explotaciones cartografiadas por el Mapa de Cultivos de Canarias.

El intento de mejorar las condiciones naturales de producción de cada zona agrícola, aprovechando al máximo la radiación solar para forzar el desarrollo vegetativo de las plantas, reforzar la calidad de los productos obtenidos y preservar los cultivos de los efectos negativos del viento, ha llevado a los empresarios agrícolas a la construcción de invernaderos en numerosos lugares del Archipiélago, especialmente en la franja de costa, la que posee las mejores condiciones térmicas para el desarrollo de la agricultura intensiva. Por ello, estas estructuras metálicas y de madera, cubiertas de películas semitransparentes o mallas de plástico, han acabado convirtiéndose en elementos destacados del paisaje cultivado, que conforma junto con las explotaciones agrarias que permanecen al aire libre, «los paisajes de la agricultura intensiva de costa». 
Figura 4. Paisaje platanero con invernaderos en la costa de Gáldar, Gran Canaria.

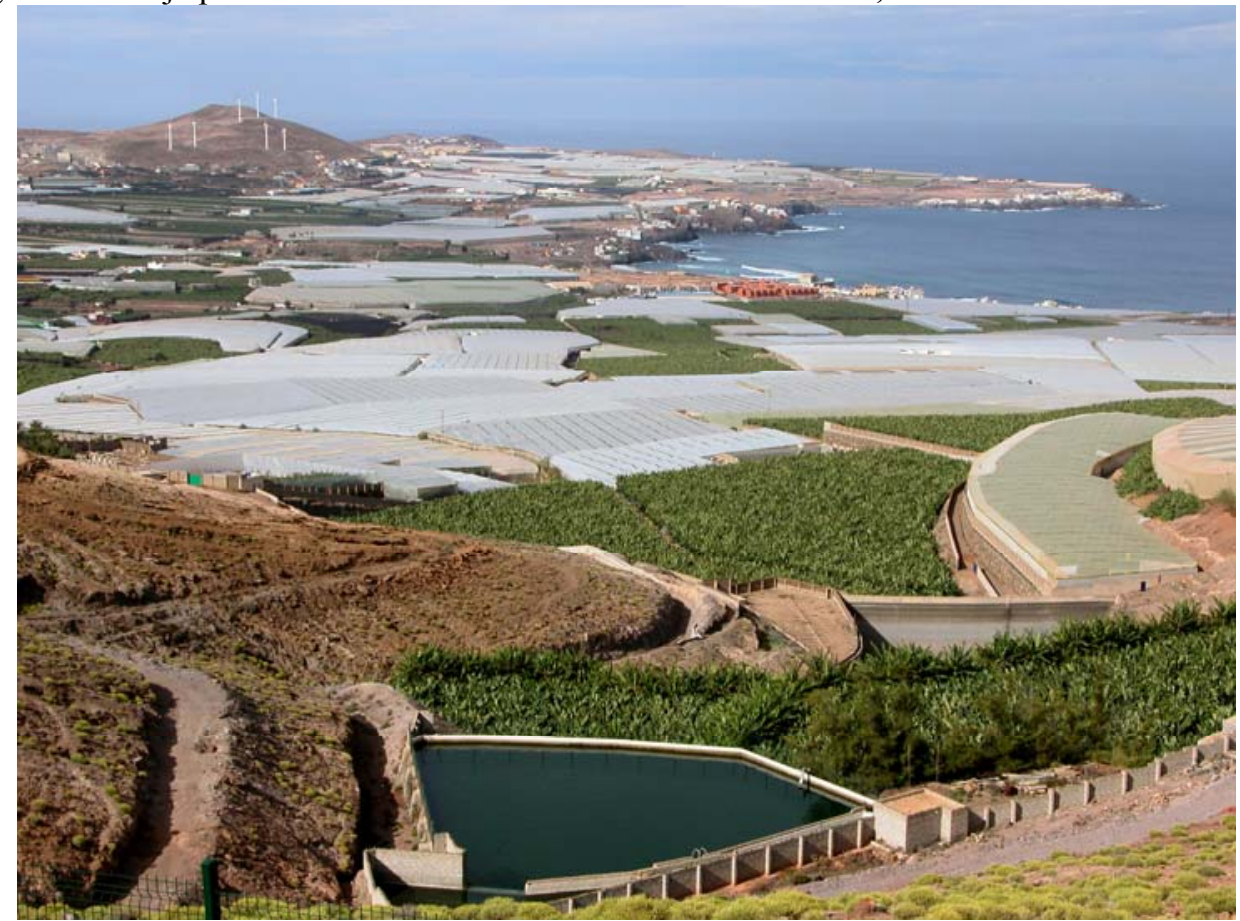

Fuente: Elaboración propia.

Así ocurre, por ejemplo, en las explotaciones plataneras del valle de Aridane, de la costa de Tejina y Valle de Guerra, Las Galletas y Rasca, de la vega de Gáldar y del valle del Golfo, que aparecen en parte sustraídas a la vista del observador bajo el blanquecino tapiz de plástico; y también sucede lo mismo con los cultivos de tomates, hortalizas, flores y plantas ornamentales, aunque en estos casos las explotaciones se sitúan desde hace años exclusivamente en el interior de los invernaderos, que en algunos lugares forman un paisaje continuo, un pequeño «mar de plástico», que se acerca más por su aspecto externo e instalaciones anejas a un singular paisaje industrial, que a un paisaje de la agricultura. Este tipo de paisaje de plástico de elevada productividad agraria y notables efectos ambientales, que además esconde los cultivos y las variaciones agrícolas bajo las cubiertas protectoras, ha terminado ocupando la mayor parte del espacio cultivado en la Aldea de San Nicolás y en los llanos costeros de Telde, Ingenio, Agüimes y Santa Lucía, en el noroeste y este Gran Canaria, respectivamente; y en menor medida algunas áreas del sur de Tenerife, en los municipios de Arico, Granadilla y San Miguel.

En la tipología específica del «paisaje de invernadero», Martín Martín (2000:106107) incluye dos ejemplos que considera representativos del mismo, como son «los invernaderos de tomates de los llanos de Arinaga», en el municipio grancanario de Santa Lucía, y «los invernaderos de plátanos de Valle de San Lorenzo, en el término 
tinerfeño de Arona, aunque en este último caso dichas explotaciones han desaparecido por completo, como consecuencia de su inadecuado emplazamiento para el desarrollo de la platanera, debido al importante descenso nocturno de las temperaturas que se registra durante el invierno, en el citado Valle. Pero teniendo en cuanta la incidencia parcial y discontinua de los invernaderos en el mapa de cultivos de las zonas bajas de las Islas; y de la diversidad de cultivos que cubren sus instalaciones, que van desde las plataneras hasta las hortalizas, pasando por las flores, las hierbas arborescentes como las papayas y los árboles frutales; y que además se distribuyen de manera casi aleatoria en los diferentes terrazgos locales; por todas estas razones resulta más conforme con la realidad geográfica actual y más coherente desde el punto de vista metodológico, establecer una sola categoría de paisaje que englobe todo este importante y dinámico conjunto agrario, tal y como se hace en este trabajo, que se podría denominar «los paisajes de la agricultura intensiva de costa» y nos olvidarnos del más limitado «paisaje de invernadero».

Los espacios dedicados en Canarias a la ganadería extensiva en el pasado han sido aquellos que por sus difíciles condiciones naturales no eran útiles para producir alimentos en secano con destino a la población insular, por su escasa pluviometría y pobreza de suelos, o por ambas causas a la vez, como ha ocurrido en numerosos predios de propiedad privada, situados en la franja árida de costa, o en las jóvenes áreas de cumbre de propiedad pública en las Islas de relieve, con suelos poco edafizados y grandes variaciones térmicas entre el día y la noche, o en las recientes y ventosas tierras de La Dehesa, en El Hierro. Pero el uso pastoril de estos lugares ha ido disminuyendo de manera progresiva desde hace varias décadas, como consecuencia de la revalorización agraria primero y turística después de las propiedades rústicas de la costa, de la demanda de mano de obra no cualificada producida por el aumento de la construcción y los servicios, de la creación de espacios naturales protegidos de uso ganadero restringido o excluido en la franja de cumbre y de la estabulación de la mayoría de los rebaños de cabras y ovejas que aún subsisten, porque su establecimiento en corrales resulta más rentable para la producción de queso y para mejorar la alimentación del ganado, que el pastoreo convencional por los derroteros aún permitidos en busca de los escasos pastos existentes.

Por otra parte, la separación territorial entre los usos agrícola y ganadero en el fragmentado espacio rural de las Islas se llevó a cabo en muchos lugares en el pasado, después de una larga etapa de conflictos, mediante la construcción de cercas de piedra o de otros materiales, que al mismo tiempo que señalaban el borde de las parcelas, o en algunos casos el límite de la propiedad, protegían los cultivos estacionales o los árboles frutales del diente de los animales. En este sentido resultan paradigmáticos los paisajes cercados de Isora y San Andrés en la «meseta» de Nisdafe de El Hierro; los paisajes del Llano de Las Cuevas en El Paso, de Las Breñas o de Llano Negro, en La Palma; o incluso el impresionante paisaje de cercos del malpaís de Boyuyo, ubicado al norte de Fuerteventura; y desde luego los miles de bancales del norte de Tenerife y La Gomera, que han servido no solo para nivelar los terrenos con el fin de cultivar mejor y evitar la 
pérdida de suelo, sino también para separar y ordenar los usos del terrazgo entre agricultores y ganaderos.

En el contexto económico actual, una parte de las tierras de cultivo abandonadas han supuesto una modificación, y en algunos casos también una ampliación, de las tradicionales áreas de pastoreo de los rebaños de cabras y ovejas que existen en las diferentes islas del Archipiélago; aunque la mayor parte de las explotaciones de dichas cabañas han acabado vinculándose a determinados enclaves, en los que los ganaderos han construido sus instalaciones de ordeño, y en su caso también de elaboración quesera o de refrigeración de la leche, conforme a la normas sanitarias establecidas por la legislación vigente para este tipo de actividades productivas, que se han visto sin duda estimuladas por la revalorización gastronómica del queso canario; y a partir de estos lugares, normalmente cercanos a las mencionadas áreas de pastos, una parte de los rebaños realizan prácticas de pastoreo de menor radio que antaño, completándose su alimentación con maíz o diferentes tipos de piensos compuestos, para estimular la salud de los animales y la producción láctea en pequeñas o medianas explotaciones de razas autóctonas cada vez más seleccionadas.

Sin embargo, los municipios de mayor concentración pecuaria de las ganaderías caprina y ovina y sus áreas de pastoreo no se han transformado por ello en paisajes ganaderos, por la escasa o nula visibilidad territorial de las modestas y puntuales instalaciones, que solo en muy pocos casos son modernas queserías, como las de Benijos y Arico, en Tenerife, y de la práctica pastoril en su demarcación o en los pagos cercanos. Por todo ello, no es posible sustentar con rigor en la realidad socioeconómica y geográfica actual de la ganadería en Canarias la existencia de ningún «paisaje ganadero», como lo hace Martín Martín en la última de las categorías paisajísticas de su clasificación, ubicando sus unidades arquetípicas en el núcleo de Teno Alto, en el macizo del mismo nombre, en Tenerife, y en el pueblo de San Andrés, en la llamada meseta de Nisdafe, en El Hierro (2000:110).

\section{DISTRIBUCIÓN Y DINÁMICA RECIENTE DE LOS CULTIVOS EN CANARIAS}

La tierra cultivada en Canarias, en el momento actual, apenas alcanza las 41.400 hectáreas, según la Estadística Agraria de Canarias 2010 de la Consejería de Agricultura, Ganadería, Pesca y Aguas del Gobierno autónomo, lo que representa solo el 5,6 por ciento de la superficie regional, repartiéndose en proporciones bastante desiguales entre el secano y el regadío y también entre las diferentes Islas, en relación con su dimensión espacial y con la importancia relativa de la actividad agraria entre los usos del suelo insulares y el abandono de las explotaciones. Sin embargo, el Mapa de Cultivos de Canarias, elaborado para las distintas islas del Archipiélago por la misma institución autonómica entre 2003 y 2008, registra una superficie cultivada sensiblemente mayor que la apuntada, pues esta se acerca a las 47.400 hectáreas, lo que supone el 6,4 del espacio regional, que se localiza en un 57,6 por ciento por encima de la curva de los 300 metros, observándose, además, en algunos casos, 
ciertas diferencias entre la extensión que ocupan los principales cultivos, según la fuente utilizada.

El reparto altitudinal de la superficie agraria es favorable a Las Medianías en el conjunto del Archipiélago, a pesar de la modesta altitud de las islas orientales, pues en dicha franja agroclimática se contabilizan 27.258,8 hectáreas de tierras cultivadas, según los datos del Mapa de Cultivos de Canarias, lo que representa el 7 por ciento de la misma, y en esta se encuentran algunos de los cultivos que más extensión ocupan y más impronta paisajística generan en la región, como el viñedo. En cambio, en la franja de costa se localizan solo 20.089,4 hectáreas de tierras cultivadas, según la mencionada fuente, lo que supone el 5,7 por ciento de la misma, aunque en esta se encuentran los cultivos más productivos, obtenidos en buena medida bajo plástico, y las explotaciones técnicamente más avanzadas de la región, así como los cultivos que más superficie registran, después de la vid, como el plátano (figura 5), producido al aire libre y en invernadero, por lo que constituye el elemento fundamental del paisaje de la agricultura intensiva de muchas áreas costeras de las Islas.

Figura 5. Proporción de superficie cultivada y abandonada en las franjas de costa y en las Medianías.

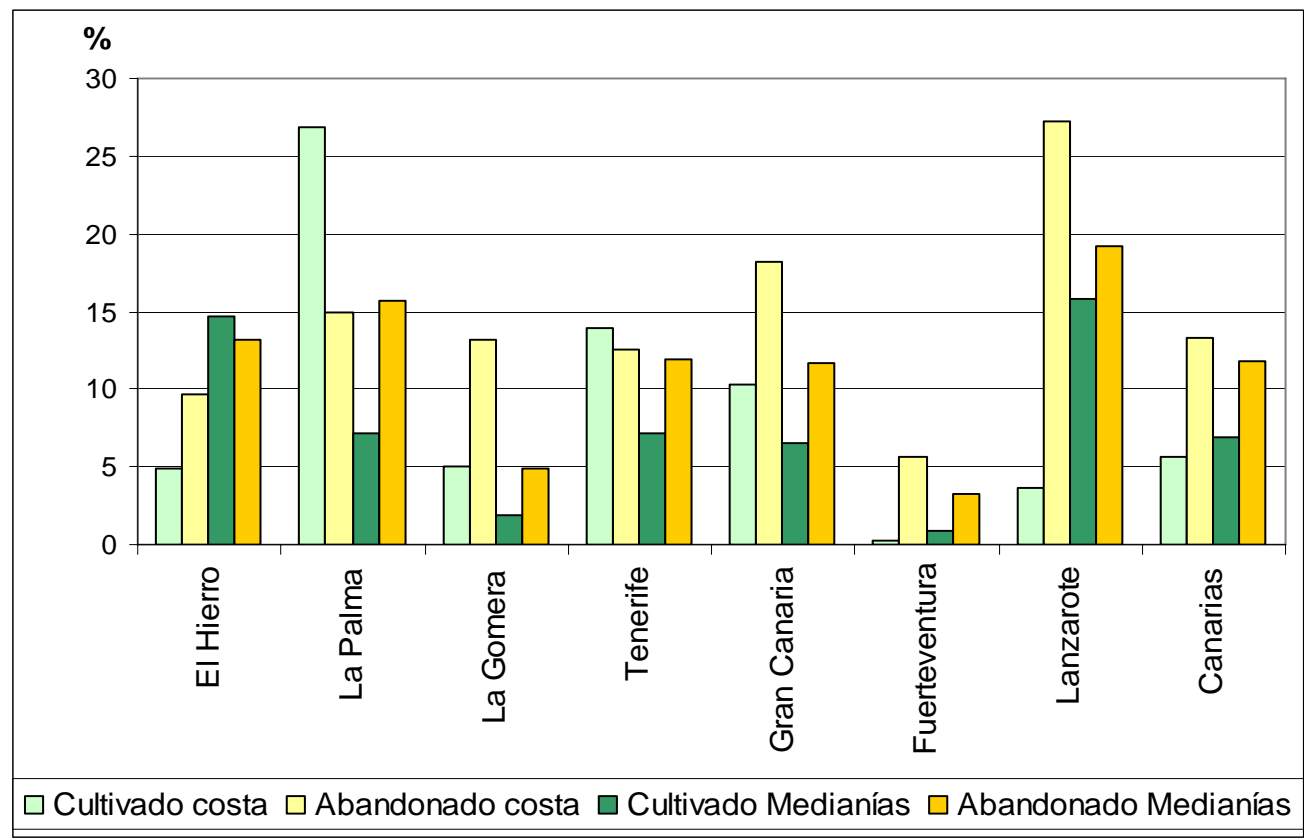

Fuente: Elaboración propia.

Sin embargo, la extensión de cultivos abandonados es algo más elevada en la costa, con 47.122 hectáreas, que en Las Medianías, con 45.960 hectáreas, aunque en términos relativos la discrepancia numérica entre ambas franjas altitudinales es mucho 
mayor (el 13,3 por ciento y el 11,7 por ciento, en uno y otro ámbito), probablemente a causa de que el retroceso del secano en las últimas décadas haya afectado más a la zona baja por sus destacadas condiciones de aridez, que a la franja más húmeda. De todos modos, la extensión de cultivos abandonados en toda la región durante el último medio siglo, según el cómputo realizado a posteriori por el Mapa de Cultivos de Canarias sobre las parcelas catastrales en las que se evidencia visualmente el cese de la actividad agraria, es muy superior a la actual superficie cultivada, pues supera las 93.000 hectáreas y supone nada menos que el 12,5 por ciento del territorio regional (figura 5). Por esta razón el paisaje del abandono agrario constituye la imagen más extendida y homogénea del espacio agrario potencial de las Islas.

La diferencia más llamativa en el cómputo específico de los cultivos se da en el caso del viñedo, que se acerca a las 8.800 hectáreas, según los datos de la primera de las fuentes oficiales mencionadas, y apenas supera las 7.500 hectáreas conforme el cálculo realizado por los técnicos del Mapa de Cultivos de Canarias, por el procedimiento cartográfico de la agregación de las parcelas catastrales ocupadas por la viña en el conjunto del Archipiélago. Pero dicha divergencia estadística de más de 1.280 hectáreas no se debe a un error de cálculo del servicio de Estadística de la citada Consejería, sino principalmente a la sobrevaloración de la superficie de viña del Registro Vitícola de Canarias, elaborado en el año 2000 por el Ministerio de Agricultura, Ganadería, Pesca y Alimentación, y entregado posteriormente a las comunidades autónomas para su gestión (Godenau y Suárez Sosa, 2004: 2).

Dicho registro conserva en su estado actual numerosas parcelas que han dejado de cultivarse desde hace tiempo y otras que se cultivan solo parcialmente (Cáceres Hernández y otros, 2004: 4), a pesar de lo cual no ha sido actualizado por la Administración autonómica, probablemente con la finalidad de mantener la cuota territorial del viñedo, en el contexto nacional, y de preservar al sector la posibilidad de continuar recibiendo el mayor número de ayudas potenciales por parte de la Unión Europea, en una región que es muy deficitaria en la producción de vino para el abastecimiento del mercado interno.

Pero también existen en algunos casos diferencias muy marcadas a favor de la superficie de cultivos contabilizada en el Mapa de Cultivos de Canarias, como ocurre por ejemplo con el grupo de los cereales y las leguminosas, que en este caso incluye además los pastos producidos de manera más o menos directa por los agricultores, en islas como La Palma o El Hierro (tablas 1 y 2), probablemente a causa de la finalidad ganadera del conjunto, por lo cual la disparidad numérica entre una y otra fuente superas las 1.300 hectáreas, aunque en realidad la comparación se establece entre unidades solo en parte coincidentes. Sin embargo, en el caso de los cultivos de papas, plátanos, tomates, flores cortadas y plantas ornamentales, cítricos y árboles frutales, las diferencias entre ambas fuentes no son tan acusadas e incluso la menor superficie computada en la Estadística Agraria 2010 puede estar relacionada en parte con la disminución de las explotaciones dedicadas a los mismos que se ha registrado en los últimos años, ya que la información cartográfica destinada a la elaboración del Mapa de Cultivos de las diferentes Islas ha sido recogida entre los años 2003 y 2008. 
Tabla. 1. Distribución de la superficie cultivada en la franja de costa en hectáreas.

\begin{tabular}{|c|c|c|c|c|}
\hline & El Hierro & La Palma & La Gomera & Tenerife \\
\hline Cereales-pastos & 39,6 & 9,6 & 15,8 & 54,0 \\
\hline Viñedos & 89,8 & 133,5 & 48,5 & 380,5 \\
\hline Papas & 1,2 & 32,4 & 63,3 & 177,3 \\
\hline Hortalizas & 6,7 & 28,1 & 16,2 & 418,2 \\
\hline Tomates & 0,1 & 0,8 & 0,8 & 558,5 \\
\hline Huerta familiar & 14,8 & 63,1 & 5,4 & 304,6 \\
\hline Huerta limpia & 31,4 & 42,9 & 57,2 & 367,0 \\
\hline F. templados & 16,6 & 4,1 & 2,9 & 11,9 \\
\hline Cítricos & 4,9 & 27,1 & 18,8 & 116,7 \\
\hline P. ornamentales & 1,1 & 4,4 & 4,1 & 433,7 \\
\hline F. subtropicales & 126,0 & 115,6 & 46,6 & 447,5 \\
\hline Plataneras & 60,0 & 2630,4 & 223,5 & $3.991,6$ \\
\hline S. cultivada & 392,2 & 3092,0 & 503,3 & $7.261,4$ \\
\hline C. abandonados & 767,2 & 1713,3 & $1.316,8$ & $6.595,5$ \\
\hline SAU & $1.159,4$ & $4.805,3$ & $1.820,0$ & $13.856,9$ \\
\hline
\end{tabular}

\begin{tabular}{|c|c|c|c|c|}
\hline & $\begin{array}{c}\text { Gran } \\
\text { Canaria }\end{array}$ & Fuerteventura & Lanzarote & Canarias \\
\hline Cereales-pastos & 101,1 & 217,3 & 528,4 & 965,8 \\
\hline Viñedos & 44,4 & 6,2 & 967,0 & $1.670,1$ \\
\hline Papas & 94,0 & 16,6 & 31,9 & 416,7 \\
\hline Hortalizas & 808,7 & 23,8 & 477,8 & $1.779,5$ \\
\hline Tomates & $1.431,0$ & 73,7 & 6,4 & $2.071,4$ \\
\hline Huerta familiar & 213,9 & 33,0 & 58,3 & 693,1 \\
\hline Huerta limpia & 446,3 & 18,0 & 0,0 & 962,8 \\
\hline F. templados & 38,9 & 6,0 & 26,1 & 106,6 \\
\hline Cítricos & 377,1 & 0,0 & 0,0 & 544,6 \\
\hline P. ornamentales & 196,4 & 0,0 & 271,8 & 911,5 \\
\hline F. subtropicales & 509,6 & 15,7 & 3,3 & $1.264,3$ \\
\hline Plataneras & $1.797,7$ & 0,0 & 0,0 & $8.703,1$ \\
\hline S. cultivada & $6.059,1$ & 410,3 & $2.371,1$ & $20.089,4$ \\
\hline C. abandonados & $10.755,6$ & $7.982,8$ & $17.990,7$ & $47.121,9$ \\
\hline SAU & $16.814,7$ & $8.393,1$ & $20.361,8$ & $67.211,3$ \\
\hline
\end{tabular}

Fuente: Mapa de cultivos de Canarias, 2003-2008 
Tabla. 2. Distribución de la superficie cultivada en Las Medianías, en hectáreas.

\begin{tabular}{|c|c|c|c|c|}
\hline & El Hierro & La Palma & La Gomera & Tenerife \\
\hline Cereales-pastos & $1.980,4$ & $1.284,5$ & 15,8 & 857,4 \\
\hline Viñedos & 262,7 & 959,3 & 48,5 & $3.126,0$ \\
\hline Papas & 35,8 & 199,2 & 63,3 & $2.679,7$ \\
\hline Hortalizas & 6,5 & 69,6 & 16,2 & 349,3 \\
\hline Tomates & 0,1 & 2,5 & 0,8 & 155,8 \\
\hline Huerta familiar & 15,9 & 242,0 & 5,4 & 999,4 \\
\hline Huerta limpia & 85,1 & 224,4 & 57,2 & $1.825,7$ \\
\hline F. templados & 370,0 & 244,7 & 2,9 & 335,3 \\
\hline Cítricos & 0,3 & 109,2 & 18,8 & 224,2 \\
\hline P. onamentales & 0,0 & 29,7 & 4,1 & 82,1 \\
\hline F. subtropicales & 23,6 & 463,9 & 46,6 & 189,1 \\
\hline Plataneras & 0,1 & 402,2 & 223,5 & 35,0 \\
\hline S. cultivada & $2.780,5$ & $4.231,2$ & 503,3 & $10.859,0$ \\
\hline C. abandonados & $2.479,6$ & $9.276,2$ & $1.316,8$ & $17.980,9$ \\
\hline SAU & $5.260,1$ & $13.507,4$ & $1.820,0$ & $28.839,9$ \\
\hline
\end{tabular}

\begin{tabular}{|c|c|c|c|c|}
\hline & $\begin{array}{c}\text { Gran } \\
\text { Canaria }\end{array}$ & Fuerteventura & Lanzarote & Canarias \\
\hline Cereales-pastos & $2.120,2$ & 12,6 & 114,7 & $6.385,6$ \\
\hline Viñedos & 228,5 & 0,6 & $1.208,6$ & $5.834,2$ \\
\hline Papas & 785,1 & 1,7 & 118,9 & $3.883,6$ \\
\hline Hortalizas & 310,2 & 0,0 & 46,1 & 797,9 \\
\hline Tomates & 18,5 & 0,0 & 0,1 & 177,8 \\
\hline Huerta familiar & 398,0 & 1,6 & 9,8 & $1.672,2$ \\
\hline Huerta limpia & $1.072,5$ & 0,1 & 813,1 & $4.078,3$ \\
\hline F. templados & 674,1 & 0,0 & 10,8 & $1.637,8$ \\
\hline Cítricos & 570,6 & 0,0 & 0,0 & 923,0 \\
\hline P. onamentales & 39,3 & 190,1 & 0,0 & 345,3 \\
\hline F. subtropicales & 127,3 & 0,2 & 0,0 & 850,8 \\
\hline Plataneras & 11,5 & 0,0 & 0,0 & 672,2 \\
\hline S. cultivada & $6.355,9$ & 206,9 & $2.322,1$ & $27.258,8$ \\
\hline C. abandonados & $11.320,1$ & 776,0 & $2.810,6$ & $45.960,1$ \\
\hline SAU & $17.676,0$ & 982,9 & $5.132,6$ & $73.218,9$ \\
\hline
\end{tabular}

Fuente: Mapa de cultivos de Canarias, 2003-2008

Por el contrario, la superficie cultivada de hortalizas se acerca a las 4.900 hectáreas en todo el Archipiélago, según la Estadística Agraria de 2010, y no alcanza las 
2.600 hectáreas en el cómputo del Mapa de Cultivos (tablas 1 y 2); aunque en este se contabilizan dos unidades de clasificación que pueden contener una parte de los cultivos de hortalizas, como son la «huerta familiar», con 2.365 hectáreas y dedicación prioritaria al autoconsumo en el entorno de las viviendas semidispersas o aisladas, especialmente en el ámbito de Las Medianías, según la definición específica de dicha figura, incluida en el manual de operaciones del mismo; y la denominada «huerta limpia», con 5.041 hectáreas, que corresponde a la agregación de las parcelas que carecían de cultivo en la fase de campo de elaboración del Mapa, pero tenían signos evidentes de estar preparadas para su siembra en el momento más oportuno del año agrícola. De todos modos, en muchos casos, esta figura operativa de aparente transición del barbecho al cultivo no es otra cosa que el comienzo del abandono agrario.

\subsection{EL REPARTO ALTITUDINAL DE LOS CULTIVOS}

La distribución regional de los diferentes tipos de cultivos, en relación con los dos grandes pisos agroclimáticos de Canarias, la zona de costa y Las Medianías, con sus diferentes dimensiones superficiales y sus correspondientes orientaciones de barlovento y sotavento, en las islas de relieve, muestra el neto predominio de unos pocos cultivos emblemáticos en cada una de estas franjas, y además, la presencia de una parte de las parcelas ocupadas por los mismos cultivos en ambas bandas, al establecer la separación entre estas mediante la convencional curva de nivel de los $300 \mathrm{~m}$ (figura 6). Esto último supone que una parte de las plantas cultivadas en el Archipiélago presentan una determinada «tolerancia» edafoclimática y que la orientación del terrazgo con respecto al flujo del alisio modifica de manera significativa las condiciones climáticas de los lugares situados a una misma cota, estableciendo un cierto «desfase» altitudinal de las áreas óptimas de producción entre las vertientes septentrional y meridional, lo que amplía el abanico de posibilidades de ubicación de los cultivos.

La zona baja de las Islas presenta al menos tres grandes sistemas agrarios con una notable personalidad agronómica y paisajística, que son el de la agricultura intensiva de regadío, destinada fundamentalmente a la exportación, que está presente en todas las islas occidentales y en Gran Canaria; el de los enarenados de piroclastos negros y arenas marinas, y el de las gavias, que se extienden por las islas de Lanzarote y Fuerteventura, en régimen de secano y de regadío, en función de las condiciones meteorológicas del año agrícola concreto y de la dotación técnica de las explotaciones llevada a cabo para la irrigación de los cultivos; aunque en los últimos quinquenios se ha extendido el uso del regadío con agua de abastecimiento público procedente de las desaladoras en la agricultura sobre arena o sobre gavias, como una forma de mantener ciertos cultivos de hortalizas destinados al abastecimiento familiar y al mercado interior, en el árido entorno de las Islas orientales. 
Figura 6. Distribución de los cultivos por las zonas de costa y Las Medianías, en Canarias.

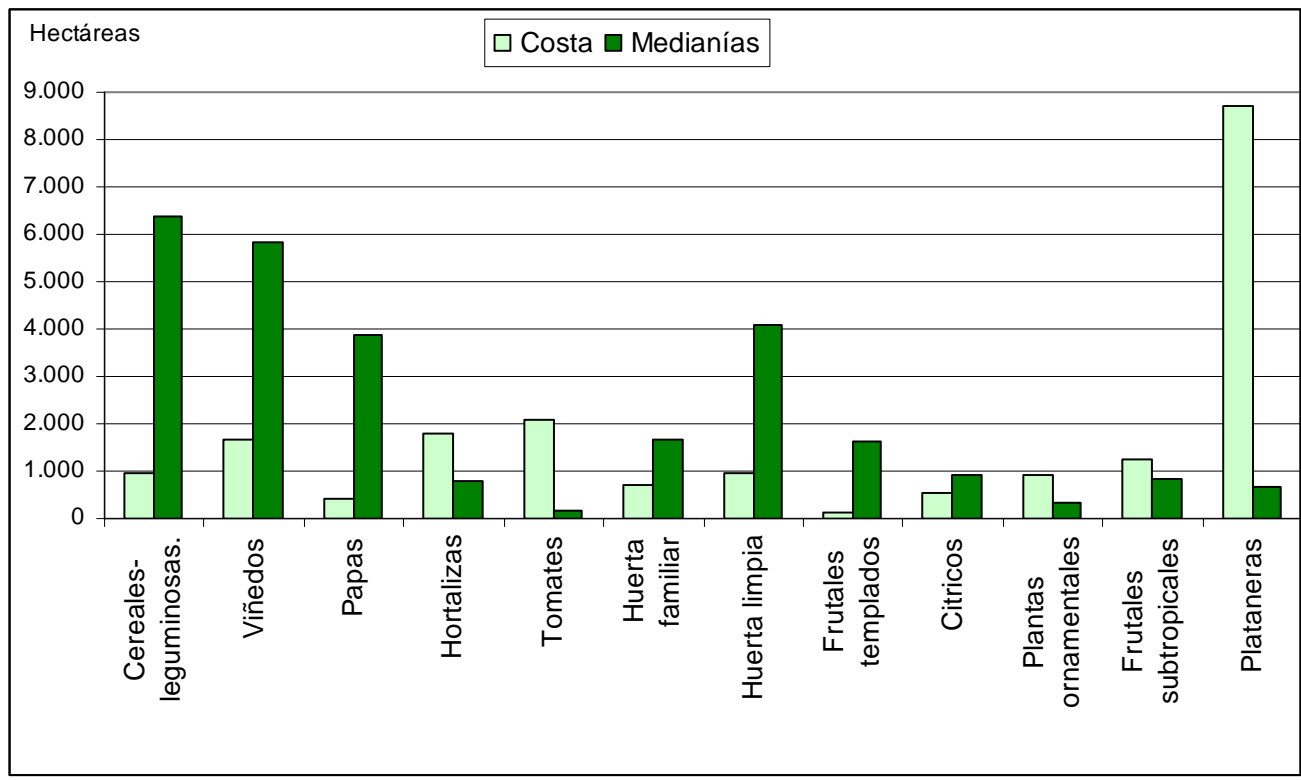

Fuente: Elaboración propia.

El plátano es el principal cultivo de la franja de costa por su extensión superficial superior a las 9.100 hectáreas, por el valor de su producción, que supera los 130 millones de euros en 2010, según las estimaciones de la Estadística Agraria de dicho año, y por su impronta territorial en las áreas agrícolas más importantes de las Islas, como en la vega de Gáldar, en Gran Canaria, en el valle de Aridane, en La Palma, o en la costa de Guía de Isora, en Tenerife. En algunos espacios especialmente abrigados de los flujos fríos del norte y noreste, el cultivo sube incluso por encima de la curva de los $300 \mathrm{~m}$, como en la Costa de Tijarafe, en La Palma, y está presente en todas las islas occidentales y también en Gran Canaria, siendo Tenerife la isla más platanera, con más del 42 por ciento de la superficie regional (tabas 1 y 2).

El panorama de la agricultura intensiva de la zona de costa lo completan los cultivos de los diferentes tipos de hortalizas, comenzando por el tomate, que se produce en todas las Islas y supera ampliamente las 2.000 hectáreas, según el Mapa de Cultivos de Canarias y se aleja de dicha cifra conforme a los datos más recientes de la Estadística Agraria de 2010 (1.700 hectáreas). La modernización del sistema de cultivo de esta solanácea ha provocado su reclusión completa bajo la cubierta protectora de los invernaderos para incrementar sus rendimientos y mejorar su calidad, como ha ocurrido también con otras hortalizas, como los pimientos y los pepinos, y con las explotaciones de flores y plantas ornamentales, lo que ha transformado por completo el paisaje agrario de algunos lugares del Archipiélago, como por ejemplo, el de la Aldea de San Nicolás de Tolentino y el de la franja oriental de Gran Canaria, donde prácticamente no existe agricultura al aire libre. La concentración de explotaciones tomate- 
ras en estos y en otros lugares de su geografía ha hecho de la citada isla la principal productora de tomates del Archipiélago. En cambio, la producción al aire libre se mantiene en una parte de los frutales subtropicales y en los cítricos, aunque estos cultivos también ascienden al ámbito de Las Medianías, especialmente en islas como La Palma, con lo que logran ampliar el ciclo productivo. Un importante ámbito de cultivo de estos árboles termófilos es el fondo ensanchado y cálido de los barrancos del suroeste de Gran Canaria, donde se ubica una destacada superficie de mangos (tabla 1).

Figura 7. Una parte de los cultivos de plátanos se han asentado sobre terrazgos artificiales. Platanera en Tazcorte, La Palma.

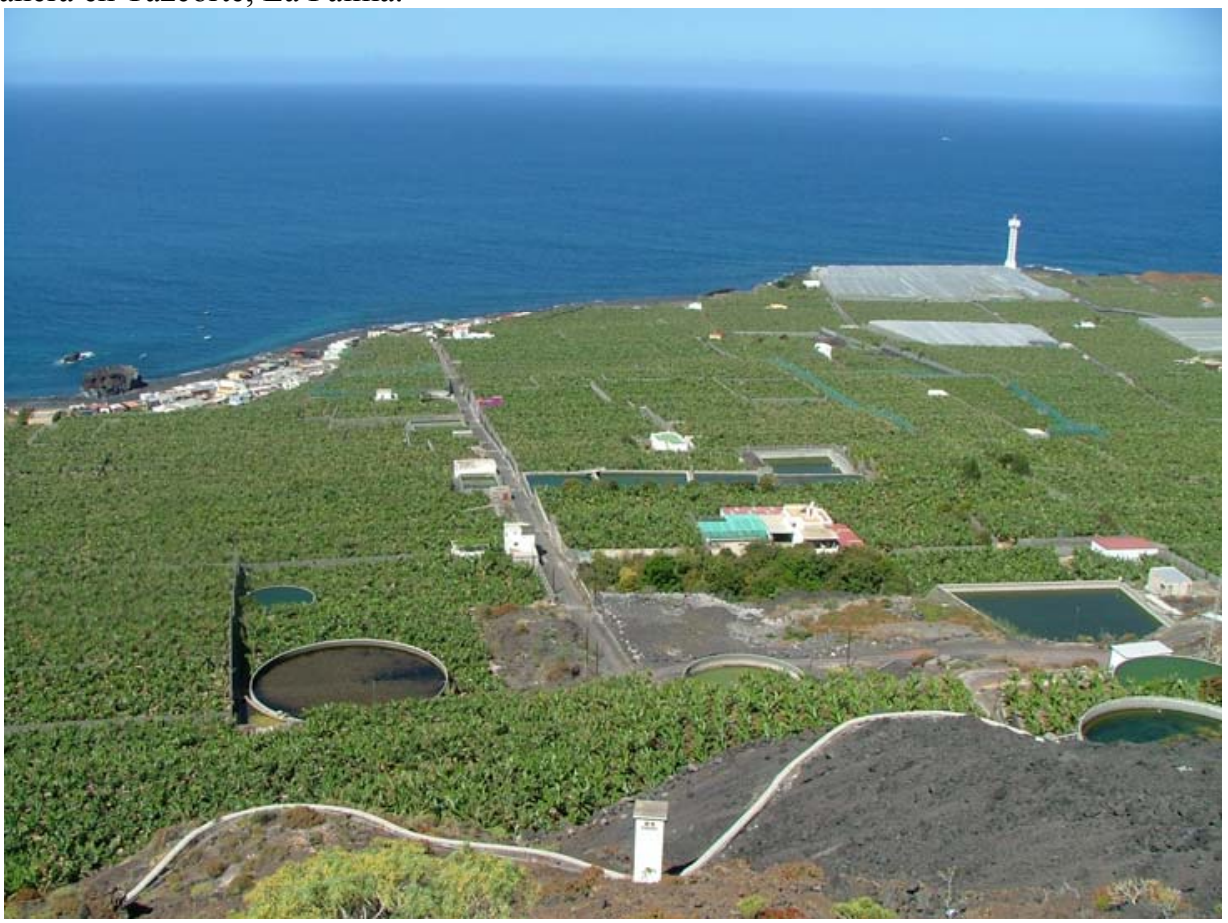

Fuente: Elaboración propia.

En las áridas islas orientales, los agricultores idearon en el pasado dos sistemas agrarios originales, los enarenados y las gavias, para aprovechar los escasos recursos hídricos disponibles en Lanzarote y Fuerteventura y luchar contra los efectos de la aridez sobre la austera agricultura. Por otra parte, la modesta altitud del relieve de ambas islas, que no alcanza los $700 \mathrm{~m}$ en el primer caso y apenas llega a los $800 \mathrm{~m}$ en el segundo, es la responsable del emplazamiento de la mayor parte de sus cultivos actuales en la zona de costa y de la utilización casi exclusiva de los mencionados sistemas de cultivos, aunque contando con el apoyo ocasional o sistemático del regad- 
ío, para producir algunos cereales y leguminosas, hortalizas, papas, alfalfa, henequén, frutales templados, y sobre todo viña, en el caso de Lanzarote, lo que da lugar a un original paisaje de la agricultura, en el que destacan más los elementos constitutivos del sistema agrario, como son las arenas marinas, los piroclastos negros, las paredes, piedras o bardos protectores o los caballones de las gavias, que los propios cultivos; aunque esto se debe también al amplio marco de plantación que necesitan las plantas para sobrevivir con poca humedad, y a la importancia del abandono agrario, que es el más elevado del Archipiélago, en términos relativos, pues supera el 88 por ciento en el caso de Lanzarote y el 95 por ciento en el de Fuerteventura, y deja al descubierto la mayor parte de los enarenados y de las gavias, casi vacíos de vegetación natural, a pesar de la ausencia de labores agrícolas.

Figura 8. Las gavias de Fuerteventura son una especialización del sistema agrario para aprovechar las aguas de escorrentía.

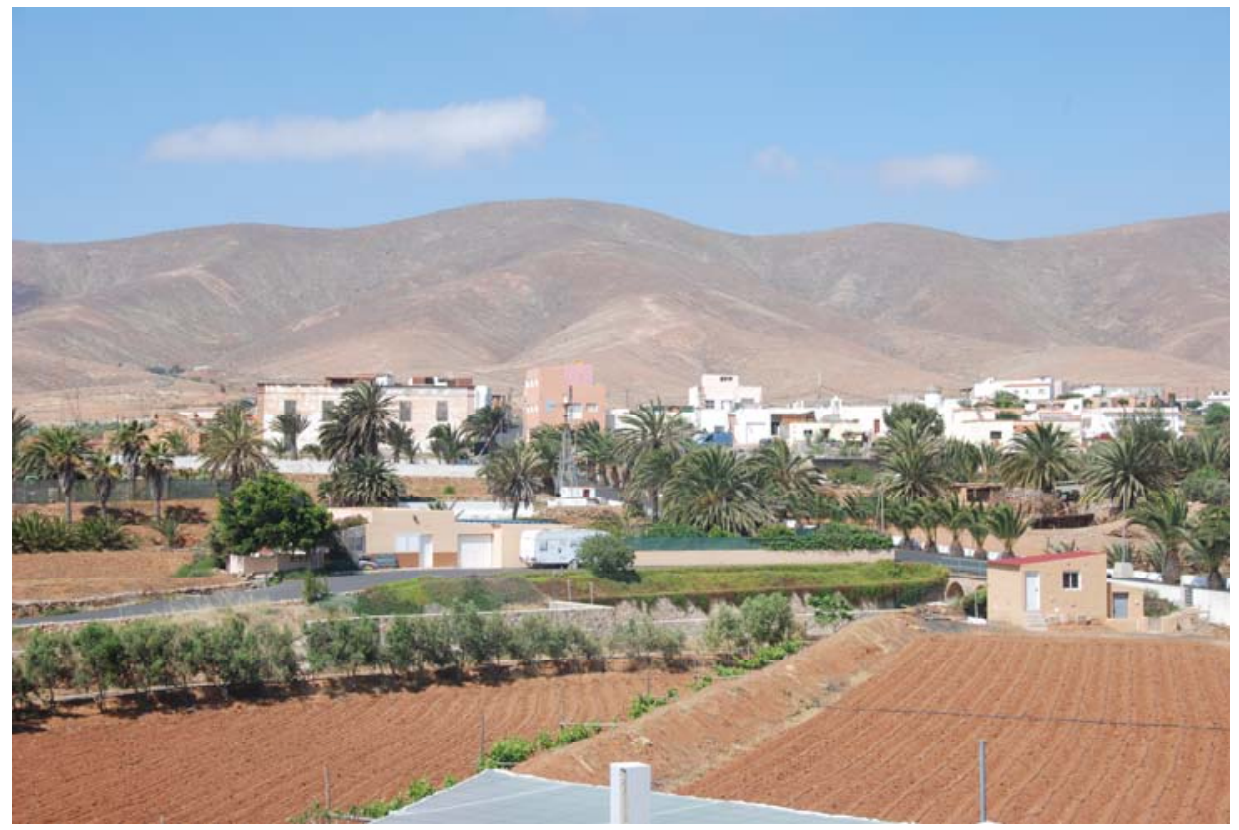

Fuente: Elaboración propia.

La zona de Las Medianías de las islas de relieve, definida de manera convencional por los geógrafos como la franja de ocupación humana situada entre las curvas de nivel de 300 o $400 \mathrm{~m}$ y la cumbre o el monte, presenta también una notable diversidad agrícola, en función de la orientación septentrional o meridional del territorio y de la altitud del ámbito de análisis, ya que el límite superior de los cultivos y del poblamiento tradicional varía de los 800-1.000 m en la vertiente de barlovento a los 1.500 $1.700 \mathrm{~m}$ en la de sotavento. Por ello, la combinación de la humedad ambiental, el 
volumen de precipitaciones, la temperatura y las horas de sol anuales con el tipo de suelo de cada área insular da lugar a la existencia de numerosos ámbitos territoriales o ecotopos, diferenciados por sus condiciones naturales específicas, sus formas de ocupación del suelo, sus aprovechamientos agrarios de secano y regadío y sus paisajes de la agricultura. A pesar del peso del abandono agrario y del intenso proceso de urbanización que ha afectado en las últimas décadas a esta franja emblemática del espacio rural de las Islas, la zona de Las Medianías posee más del 57 por ciento de la tierra cultivada en la región, aunque el valor de su producción agraria no alcanza ni la cuarta parte del total.

La diversidad de ámbitos cultivados va desde las Islas más lluviosas, como La Palma, a las más áridas, como Lanzarote y Fuerteventura, en las que apenas se insinúan los rasgos agroclimáticos de Las Medianías en sus tierras situadas por encima de la franja de costa, por lo que hemos introducido para definirlas el término de «protomedianías», que registra más de 2.300 hectáreas cultivadas (o en disposición de estar cultivadas) en Lanzarote y solo 207 hectáreas en Fuerteventura. Pero en el interior de cada isla también existen diferencias en el mapa de ocupación del suelo y en los paisajes de la agricultura entre las fachadas de barlovento y sotavento; e incluso dentro de las mismas entre las medianías altas, más frías y húmedas, y las medianías bajas, más cálidas y secas, por lo que presentan aprovechamientos diferentes. Por otra parte, en algunos lugares de las Islas, la impronta de los sistemas de cultivo es más importante que los condicionantes edafoclimáticos en la determinación de las unidades de uso agrario y en la tipificación de los paisajes, como ocurre, por ejemplo, con los cultivos sobre piroclastos blancos o jables del sur de Tenerife, o sobre piroclastos negros o lapillis en Lanzarote, La Palma o El Hierro.

La resultante espacial de las numerosas variables anteriores en la franja de Las Medianías se concreta en cuatro tipos de unidades, diferenciadas en relación con los cultivos existentes, con las técnicas agrarias aplicadas y con la organización del espacio cultivado: «las medianías de barlovento», «las medianías de sotavento», «los cultivos sobre jable»y «los cultivos sobre lapillis». Sus principales características, sus cultivos más destacados, así como su ubicación espacial se exponen a continuación.

En este amplio conjunto de ámbitos agrarios y de asentamientos demográficos de Las Medianías, que se extiende por todas las islas del Archipiélago, aunque con diferente extensión superficial en cada una de estas, destaca el aprovechamiento de orientación ganadera de los «cereales, leguminosas y pastos», con una superficie cercana a las 6.400 hectáreas y emplazamiento elevado, según el Mapa de Cultivos, que se localiza sobre todo en las islas de Gran Canaria, El Hierro y La Palma, por orden de amplitud. Le siguen por su importancia superficial los cultivos de viña y papas (tabla 2), repartidos también por todas las Islas, aunque la extensión de los mismos en Fuerteventura es meramente simbólica, y en cambio, Tenerife reúne más del 53 por ciento del viñedo y el 69 por ciento de la superficie cultivada de papas en la región.

Alcanza asimismo una llamativa extensión la denominada «huerta limpia», que es una figura técnica que agrupa más de 4.000 hectáreas de tierras en disposición de ser 
aprovechadas por cultivos estacionales, según la definición del Mapa de Cultivos, lo que podría incrementar de manera significativa la superficie de las hortalizas destinadas al mercado interior, acercándose sus datos a los incluidos en la Estadística Agraria de 2010 para este importante sector agroalimentario, o engrosar la superficie del abandono agrario. Por el contrario, la «huerta familiar» dedica su producción de hortalizas y algunos árboles frutales en pequeñas parcelas, situadas junto a las viviendas individuales o semidispersas, al consumo de la unidad familiar, da lugar a un paisaje característico de Las Medianías de barlovento, que combina edificaciones autoconstruidas, parcelas cultivadas, antiguos caminos rurales que han sido asfaltados o transformados en calles y abandono agrario.

Las medianas y pequeñas explotaciones regulares de los diferentes tipos de frutales y los numerosos ejemplares individuales de los mismos que se producen en Las Medianías superan las 3.400 hectáreas (tabla 2), aunque en algunos casos el amplio marco de plantación de los árboles incrementa de manera engañosa las estadísticas de la superficie cultivada, como ocurre, por ejemplo, con las semiabandonadas higueras en la isla de El Hierro, que suman unas 370 hectáreas junto con las escasas parcelas cultivadas de manzanas que existen en la «meseta» central de dicha isla. Ambos tipos de frutales templados son los que más extensión ocupan en todo el Archipiélago, pues superan las 1.600 hectáreas, siendo Gran Canaria con casi 700 hectáreas la isla con más superficie cultivada, aunque en la misma dominan las manzaneras y los frutales de pepita destinados al mercado insular y regional sobre las higueras, que casi han desaparecido. También es esta isla la que más extensión de cítricos posee, a la que siguen a una considerable distancia Tenerife y La Palma. En cambio, es la Isla Bonita la principal productora de aguacates de la región, con más de 500 hectáreas, que compiten de forma ventajosa con las plataneras en las áreas marginales de este cultivo en la franja baja de Las Medianías y se exportan al resto del Archipiélago y también al extranjero.

\subsection{LAS DIFERENCIAS DE CULTIVOS DE LAS FACHADAS DE BARLOVENTO Y SOTAVENTO}

Los cultivos de las fachadas de barlovento y sotavento de las Medianías son casi coincidentes, en la actualidad, aunque su ubicación es más elevada para cada uno de estos en el último de los ámbitos agroclimáticos mencionados, donde las prácticas agrícolas alcanzan las cotas más altas de la región, sobre los $1.700 \mathrm{~m}$ en Gran Canaria y Tenerife, como consecuencia de la mayor aridez de la vertiente meridional. Esto implica una mayor presencia del regadío en los diferentes terrazgos, una superficie cultivada mucho menor que la existente en la fachada de de barlovento, y también en comparación con la superficie agraria utilizada en el pasado, y por tanto, una mayor proporción de tierras de cultivo abandonadas, si tomamos como referencia general del Archipiélago lo que ocurre en la isla de Tenerife (figura 9); en la que el relieve establece, además, una separación nítida entre ambas fachadas, en relación con el flujo nororiental del alisio y con la posición del mar de nubes vinculada al mismo. 
Figura 9. Distribución de los principales cultivos de Las Medianías en las fachadas de barlovento y sotavento de la isla de Tenerife.

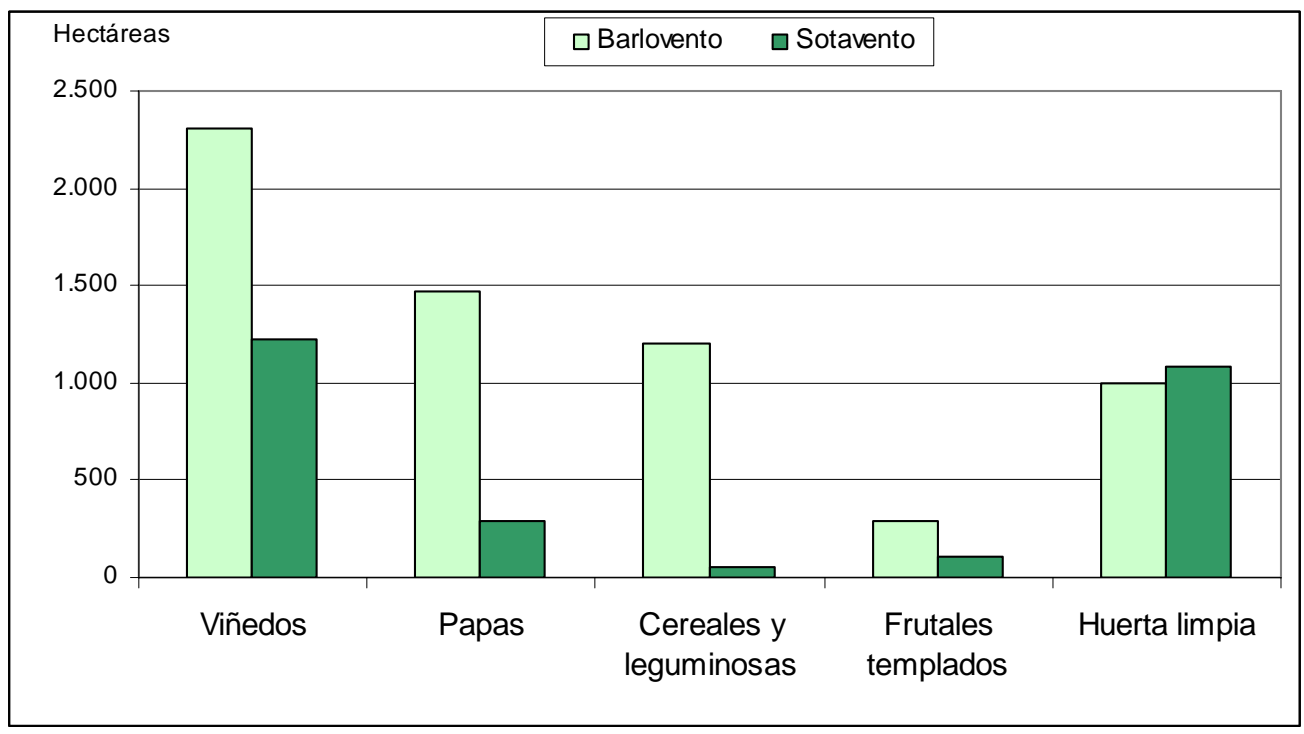

Fuente: Elaboración propia.

El principal cultivo de los dos caras agrícolas de la isla es el viñedo, aunque sus superficies son muy desiguales, siendo la extensión vitícola de la vertiente septentrional más del doble de la que posee la fachada meridional; le siguen con similares diferencias a favor de dicha fachada las papas, el grupo de los cereales y las leguminosas, una parte de las hortalizas, y finalmente, los frutales de la zona templada, que ocupan el último lugar por su extensión y difieren en sus tipos de árboles de una vertiente a la otra, en función de las temperaturas, el grado de humedad y la insolación de cada una de estas. Así, en la fachada septentrional dominan los manzanos, perales, ciruelos, castaños y nogales, e incluso, en la franja más baja, los aguacateros y los naranjos. En cambio, en la fachada de sotavento, predominan las higueras, los almendreros, los albaricoqueros y los melocotoneros y hasta la parte baja de la misma ascienden también los cítricos y los aguacateros.

En la mencionada fachada meridional de la isla de Tenerife predominan los cultivos sobre jable o enarenados construidos por los agricultores con los materiales pumíticos de color blanquecino, o piroclastos ácidos, que abundan en la comarca, como consecuencia de su origen volcánico explosivo. Dichos materiales dan lugar a un paisaje agrario original (figuras 10 y 11) y contribuyen al mantenimiento de la humedad de las parcelas construidas en la mayoría de los casos desde sus cimientos, aportando incluso el suelo agrario que falta, en un territorio de notable pendiente, escasas precipitaciones y elevada insolación. Este singular terrazgo artificial, formado 
por miles de huertas de modestas dimensiones, que se ubican entre los $300 \mathrm{~m}$ y los $1.000 \mathrm{~m}$ de altitud, aunque en algunos lugares como Vilaflor desbordan estos límites, se especializó en la producción de papas extratempranas destinadas a la exportación al Reino Unido, a partir de los años cuarenta del siglo pasado.

Figura 10. Distribución de los principales cultivos sobre jable en Tenerife.

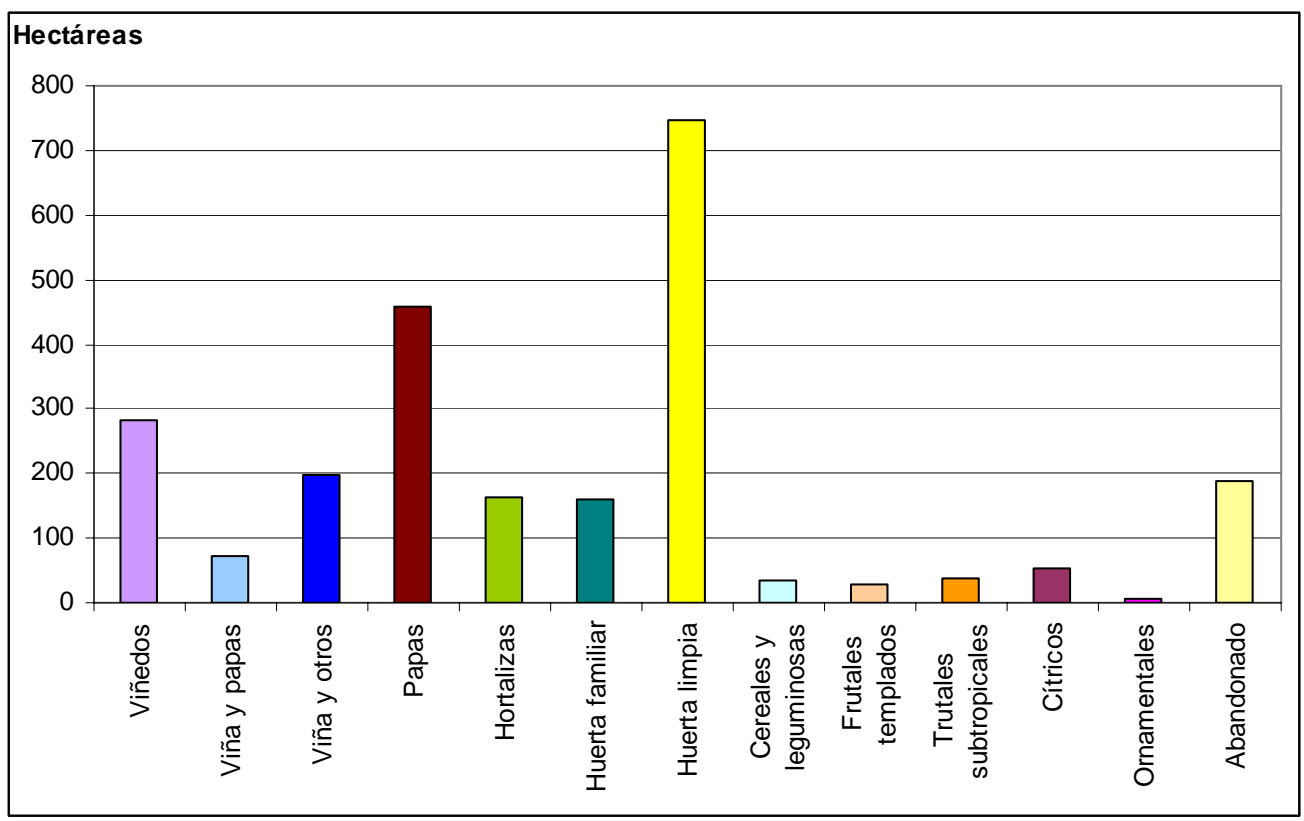

Fuente: Elaboración propia.

Este cultivo sobre jable se ha mantenido hasta la actualidad como el más importante de Las Medianías de sotavento de Tenerife por su extensión (figura 10), aunque su superficie ha disminuido de manera considerable una vez que ha cesado el mencionado flujo comercial dirigido al exterior, desde finales de los años setenta, orientándose la producción a partir de entonces exclusivamente al mercado interior. Pero el retroceso de las papas ha sido cubierto solo en parte por el cultivo de la vid, que se ha extendido sobre las mismas parcelas, en muchos casos en régimen asociado con este tubérculo o con otras plantas; por las hortalizas y los numerosos y variados huertos familiares, y por distintos tipos de frutales templados o subtropicales, como naranjos, aguacateros y melocotoneros, además de higueras. Por ello, la superficie actual de enarenados abandonados y de la denominada «huerta limpia», o parcela carente de cultivos que está a la espera de su posible utilización agrícola o de su abandono definitivo, supera el 38 por ciento de la superficie agraria utilizada en el sistema agrario de enarenados de Las Medianías meridionales de Tenerife, que se acera a las 2.500 hectáreas, según el Mapa de Cultivos de Canarias. 
En cambio, la proporción de enarenados de piroclastos básicos o lapillis negros que han dejado de ser cultivados, en las últimas décadas, según la fuente anterior, en la modesta franja agroclimática situada por encima de los $300 \mathrm{~m}$ en las islas de Fuerteventura y Lanzarote, dentro del ámbito que hemos propuesto denominar «las protomedianías», ha sido muy superior a la registrada en Tenerife, especialmente en la primera de las islas mencionadas, donde la agricultura apoyada sobre dicho sistema agrario ha sido muy escasa y casi ha desaparecido en el presente.

Figura 11. Distribución de los paisajes de la agricultura en Tenerife

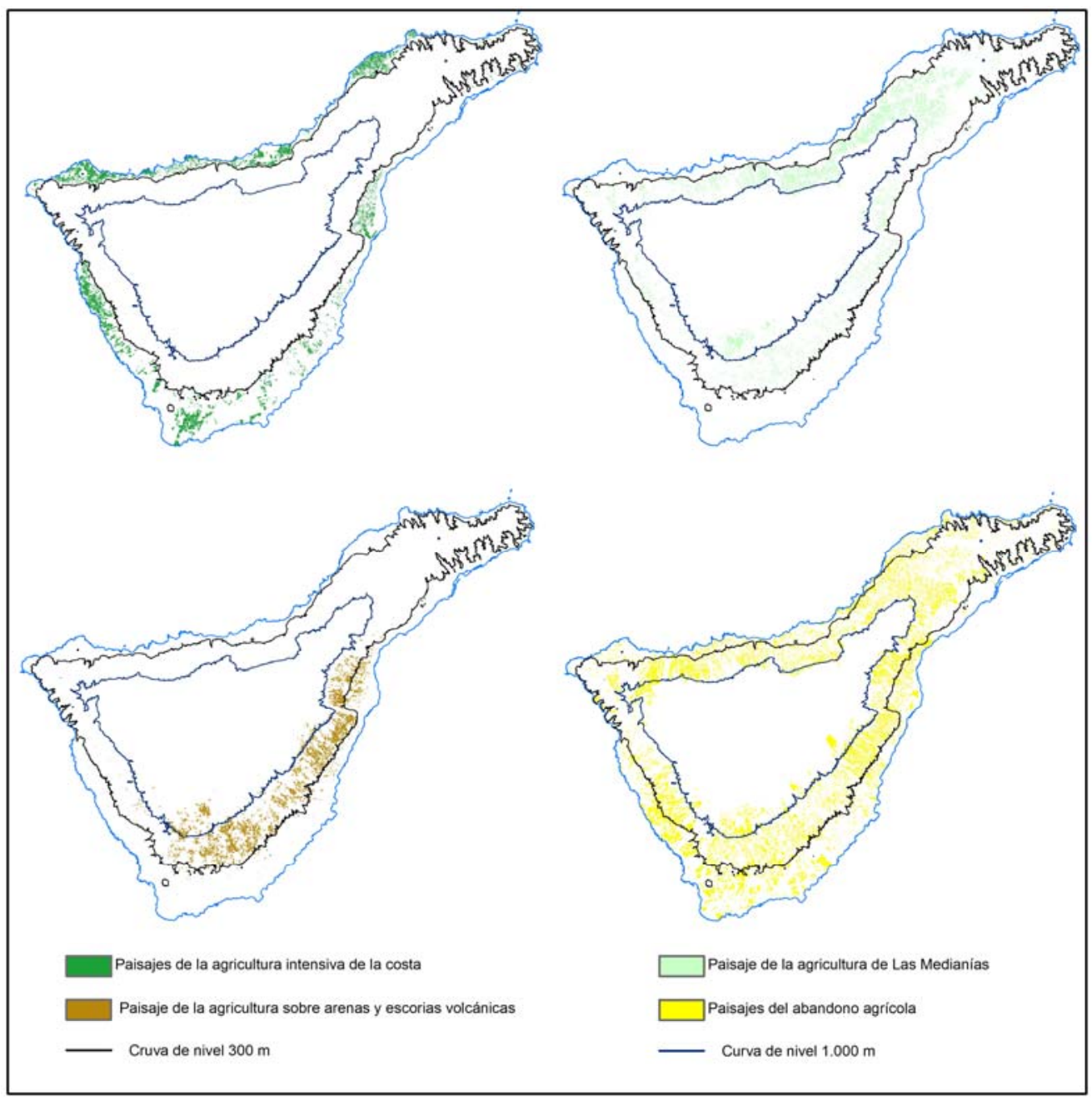

Fuente: Elaboración propia. 
En el caso de Lanzarote, que es la isla canaria de los enarenados por excelencia, con más de 3.500 hectáreas en activo en el presente, el retroceso de la tierra cultivada sobre dicho sistema, en el mismo periodo de tiempo, supera las dos terceras partes de la superficie agraria utilizada que registra el Mapa de Cultivos de Canarias (20032008), la cual alcanza las 4.200 hectáreas. Sin embargo, los cultivos que se mantienen en este enclave más húmedo, en el árido contexto insular de Lanzarote, son fundamentalmente las hortalizas, destinadas al consumo interior, con más de la quinta parte del terrazgo tradicional cartografíado, que se acerca a las 900 hectáreas contando con las características explotaciones de cebollas y batatas, a las que se suman las papas, las leguminosas y la viña, que aparece también asociada a la horticultura e incluso a las plantaciones de tuneras dedicadas a la cría de la cochinilla.

\subsection{EL REPARTO INSULAR DE LOS CULTIVOS Y DEL ABANDONO AGRARIO}

Como síntesis de todo lo anterior, el reparto de la superficie cultivada y abandonada por islas es relativamente proporcional a la extensión de estas (tablas 1 y 2), de manera que Tenerife, con 18.120,4 hectáreas cultivadas es la isla con mayor espacio agrario del Archipiélago y mayor diversidad agrícola, según el Mapa de Cultivos de Canarias, y también la que posee más extensión de tierras de cultivo abandonadas, en la actualidad, pues las mismas se acercan a las 25.000 hectáreas. Sin embargo, la isla que tiene menos superficie agraria no es El Hierro, como podría suponerse, sino Fuerteventura, la segunda isla del Archipiélago por su dimensión territorial, pues apenas alcanza las 600 hectáreas; y en cambio, supera las 8.700 hectáreas de tierras de cultivo abandonadas en el interior de varios miles de gavias, cercadas por caballones preparados sobre todo por la Administración para la llegada ocasional de las aguas de escorrentía, procedentes de las escasas precipitaciones que caen en la isla, y mitigar así la erosión de los suelos de los paisajes áridos más llamativos de Canarias, que han sido incluidos en el catálogo de reservas de la biosfera de la Unesco

Por el contrario, Lanzarote ha sido la isla con la mayor superficie agraria relativa de la región, a pesar de su climatología adversa similar a la de Fuerteventura, pues los cultivos de secano han ocupado históricamente casi la tercera parte de su territorio, unas 25.500 hectáreas, gracias a la abundancia relativa de suelos agrarios, a la suavidad orográfica del mismo y a la temprana introducción del enarenado, que ha posibilitado una producción agrícola austera y limitada en un medio muy árido. Pero en las últimas décadas, la superficie cultivada en la denominada Isla de los Volcanes se ha reducido a menos de la quinta parte, a causa del desarrollo turístico y de la mejora general del nivel de vida que este ha propiciado.

Un elevado grado de ocupación agraria histórica ha tenido también La Palma, según la reiterada fuente cartográfica regional, con un porcentaje cercano al 26 por ciento de su territorio y unas 18.300 hectáreas de superficie utilizada, a pesar de su compleja e inclinada orografía y de la escasez de terrenos llanos, lo que ha obligado a los agricultores a realizar un intenso trabajo de abancalamiento del terrazgo para poder cultivar la tierra y aprovechar los recursos hídricos potenciales de la isla, que 
son los más importantes del Archipiélago, en términos relativos. En las últimas décadas, el abandono del secano ha provocado una reducción de la superficie cultivada de unas 11.000 hectáreas, lo que representa una pérdida superior al 60 por ciento sobre el mapa tradicional de cultivos. A pesar de ello, la isla conserva todavía la mayor proporción de tierra cultivada de la región, con el 10,4 por ciento de su superficie y más de 7.300 hectáreas productivas, en las que destacan las plataneras, los viñedos y los aguacateros, entre otros cultivos.

Figura 12. Distribución de los paisajes de la agricultura en las islas periféricas occidentales y Gran Canarias.

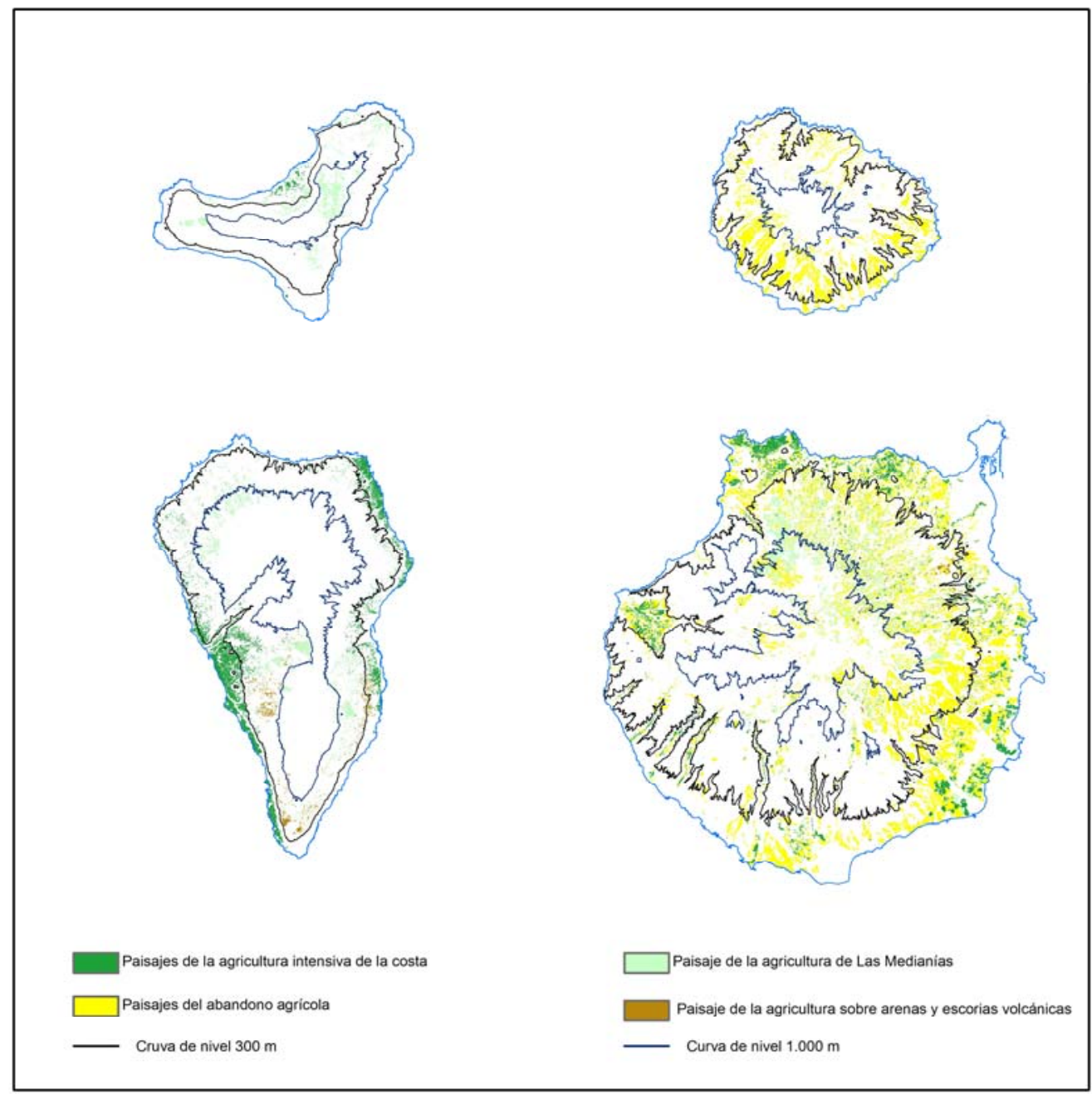

Fuente: Elaboración propia. 
Una disminución muy llamativa también, superior al 72 por ciento, ha experimentado en la misma etapa la superficie cultivada de La Gomera (Figura 12), la isla de los barrancos y de los bancales, hasta alcanzar en el presente unas 1.000 hectáreas, según el citado Mapa de Cultivos de Canarias, lo que la sitúa en el penúltimo lugar del ránking agrario de la región, a una considerable distancia de la isla que le sigue en orden ascendente, que es El Hierro, con casi 3.200 hectáreas de tierras agrícolas (tablas 1 y 2). El retroceso agrario de la Isla Colombina se debe fundamentalmente al abandono de varios miles de bancales de secano que escalan las laderas de los barrancos del norte de la isla, con el objeto de ensanchar el terrazgo agrícola que falta en el fondo de los mismos y de las numerosas y pequeñas parcelas situadas en los estrechos y empinados interfluvios existentes entre los profundos barrancos del sur de La Gomera. En cambio, el mencionado dato comparativo de la superficie cultivada en la isla de El Hierro está en parte distorsionado por la inclusión de las 1.980,4 hectáreas correspondientes al grupo de los «cereales, leguminosas y pastos», destinado a la alimentación ganadera, en el cómputo general de las tierras de cultivo, según la mencionada fuente cartográfica.

Gran Canaria es la segunda isla del Archipiélago por la extensión de sus tierras cultivadas, que se aproximan a las 12.500 hectáreas en la actualidad y superan incluso la cota de los $1.700 \mathrm{~m}$ de altura, en la desforestada zona de cumbre, lo que representa casi el 8 por ciento de la superficie insular. Pero en el pasado reciente la superficie agraria utilizada en la isla alcanzó el 22,1 por ciento de su territorio, según el registro cartográfico de parcelas del Mapa de Cultivos de Canarias, aprovechando sus importantes recursos hídricos tradicionales, que cubrieron más de la mitad del regadío de la región hasta los años cincuenta. Sin embargo, en las últimas décadas, el retroceso de las tierras cultivadas ha sido espectacular, especialmente en el ámbito del secano, donde se han dejado de cultivar más de 22.000 hectáreas, lo que ha supuesto una pérdida del 64 por ciento de la superficie agraria insular (figura 12). Aunque se ha producido también en la misma etapa una importante modernización de las explotaciones de regadío, que se refleja en la extensión de los invernaderos a la mayor parte de los cultivos de la zona baja, como plátanos, tomates, hortalizas, frutales y las flores y plantas ornamentales, destinados a la exportación, y asimismo en la transformación de numerosas explotaciones tradicionales de Las Medianías, para dedicarlas al abastecimiento del mercado interior de la isla, e incluso del Archipiélago.

\section{TIPIFICACIÓN DE LOS PAISAJES DE LA AGRICULTURA DE CANARIAS}

La distribución insular de los cultivos, expuesta en las páginas precedentes, con sus diferentes sistemas agrarios, adaptados en mayor o menor medida a las condiciones naturales del territorio y a las exigencias de modernización productiva de la agricultura moderna, como ocurre con la generalización de los invernaderos; y también de las antiguas y numerosas parcelas de cultivo abandonadas a causa de la pérdida de operatividad económica, configuran en el Archipiélago un conjunto de paisajes humanos vinculados a la actividad agrícola actual o histórica que resultan difíciles de 
clasificar. Ello se debe, en primer lugar, a la modesta carga agraria de la región, que apenas supera el 6 por ciento de la superficie de las Islas si seguimos los cálculos del mencionado Mapa de Cultivos de Canarias, y también a la elevada fragmentación del terrazgo agrícola, a la dispersión espacial de los cultivos, e incluso a la intensa urbanización del territorio en las últimas décadas, que ha acabado imponiendo su imagen edificada sobre la anterior superficie cultivada. Asimismo, en muchas áreas agrícolas, el sistema de cultivo construido por los agricultores para garantizar el aprovechamiento de la tierra es mucho más visible desde el punto de vista paisajístico que los propios cultivos, que pueden resultar incluso secundarios para su tipificación, como ocurre, por ejemplo, con los diferentes tipos de enarenados que existen en Canarias, o con la estructura de las parcelas vinculada a las gavias en Fuerteventura y Lanzarote. Sin embargo, la importante pendiente que poseen casi todas las islas del Archipiélago las convierte en auténticos escenarios, lo que facilita la visibilidad de los diferentes usos y aprovechamientos del territorio para cualquier observador y contribuye con ello a facilitar la internalización y conceptualización de los paisajes agrarios como referentes destacados o huellas en la memoria individual o colectiva de la población insular (Vázquez Varela y Martínez Navarro, 2008: 6).

Las anteriores consideraciones acerca de las dificultades inherentes a la tipificación de los paisajes de la agricultura de Canarias, planteadas en alguna medida por los autores a los que hemos hecho referencia con anterioridad (Álvarez Alonso, 1993; Martín Martín, 2000), nos han llevado a cuestionar el papel exclusivo de los cultivos como elemento definidor de las unidades de clasificación paisajística del Archipiélago, teniendo en cuenta la fragmentación parcelaria y la dispersión del mapa de cultivos de la región; y a valorar influencia de otros elementos como los materiales volcánicos usados, que en muchos casos resultan más visibles que los propios cultivos, los sistemas agrarios existentes en las Islas, las técnicas de cultivo utilizadas en la diferentes áreas agrícolas, e incluso determinadas configuraciones culturales como Las Medianías a la hora de formalizar la propuesta operativa de paisajes agrarios que presentamos en este trabajo, compuesta por cinco grandes tipos, que están presentes en la mayoría de las Islas y son los siguientes: 1) los paisajes de la agricultura intensiva de la costa; 2) los paisajes de la agricultura sobre arenas y escorias volcánicas; 3 ) los paisajes de la agricultura de la aridez de Fuerteventura y Lanzarote; 4) los paisajes de la agricultura de Las Medianías; y finalmente, 5) los paisajes del abandono agrícola (figuras 11 y 12).

\subsection{LOS PAISAJES DE LA AGRICULTURA INTENSIVA DE LA COSTA}

Este grupo genérico de paisajes se encuentra situado en las áreas más llanas de la zona baja de la mayoría de las islas del Archipiélago, sobre terrazgos artificiales más o menos continuos y de cierta extensión, pues solo falta en Lanzarote y Fuerteventura; y corresponde a los cultivos de regadío y orientación exportadora, como el plátano, que se produce al aire libre y en invernadero, y domina el paisaje en numerosos lugares; y diferentes tipos de hortalizas, como tomates, pimientos, pepinos, calabaci- 
nes, ciertos frutales, flores y plantas ornamentales, que se cultivan exclusivamente en invernadero, en explotaciones muy tecnificadas y de dimensiones mucho mayores que las de los cultivos tradicionales, por lo que tienen un notable impacto paisajístico, especialmente en las islas de Tenerife y Gran Canaria.

\subsection{LOS PAISAJES DE LA AGRICULTURA SOBRE ARENAS Y ESCORIAS VOLCÁNICAS}

Este grupo de paisajes está presenta también en todas las islas del Archipiélago, salvo en La Gomera, que no posee vulcanismo cuaternario. Es el resultado de la utilización agrícola de los materiales volcánicos de proyección aérea más jóvenes y finos, como piroclastos y escorias; o de las arenas organógenas de origen marino, esparcidas por el viento en algunos lugares, para la construcción de diferentes tipos de enarenados, caletas, huecos o breñas. Estos originales sistemas agrarios han posibilitado el aprovechamiento de los litosuelos y caracterizan el paisaje humanizado de muchas áreas de las Islas, por encima de los cultivos que poseen. Forman parte de este paisaje agrario de arenas y escorias los cultivos sobre «jable» o arena de origen marino de Lanzarote; los diversos cultivos sobre enarenados negros (naturales y artificiales) de Lanzarote (figura 12); los cultivos sobre «jable» o piroclastos volcánicos de Tenerife (figura 11); los cultivos de viña y frutales sobre escorias y enarenados negros de La Palma; y los cultivos de viña sobre enarenados negros de El Hierro (figura 12).

\subsection{LOS PAISAJES DE LA AGRICULTURA DE LA ARIDEZ DE FUERTEVENTURA Y LANZAROTE}

Los paisajes de este grupo de cultivos se localizan sobre todo en la isla de Fuerteventura, y en menor medida en la de Lanzarote, y están formados por un original sistema agrario de aprovechamiento de las escorrentías ocasionales de las precipitaciones torrenciales, para conducirlas a las parcelas cercadas por caballones de tierra compactada, que es característico de las zonas áridas, y en la isla majorera recibe los nombres locales de «gavia», «natero»o «bebedero», en función del asentamiento de las parcelas beneficiarias del agua desviada con respecto a la ubicación de los cauces de los barrancos que las abastecen en las avenidas. Sin embargo, en la actualidad, la mayor parte de las 7.615, 75 hectáreas de construcciones de este tipo que existen en ambas islas poseen escasa funcionalidad agraria, según el Mapa de Cultivos de Canarias, porque han dejado de ser cultivadas en el 90,1 por ciento de su superficie. Pero desempeñan un destacado papel paisajístico y cumplen una importante misión medioambiental en la lucha contra la erosión, en la recuperación de la vegetación natural y en la recarga de los esquilmados acuíferos, sobre todo en la isla de Fuerteventura (figura 13), convertida recientemente por ello en Reserva de la Biosfera. 
Figura 13. Distribución de los paisajes de la agricultura en las islas periféricas orientales

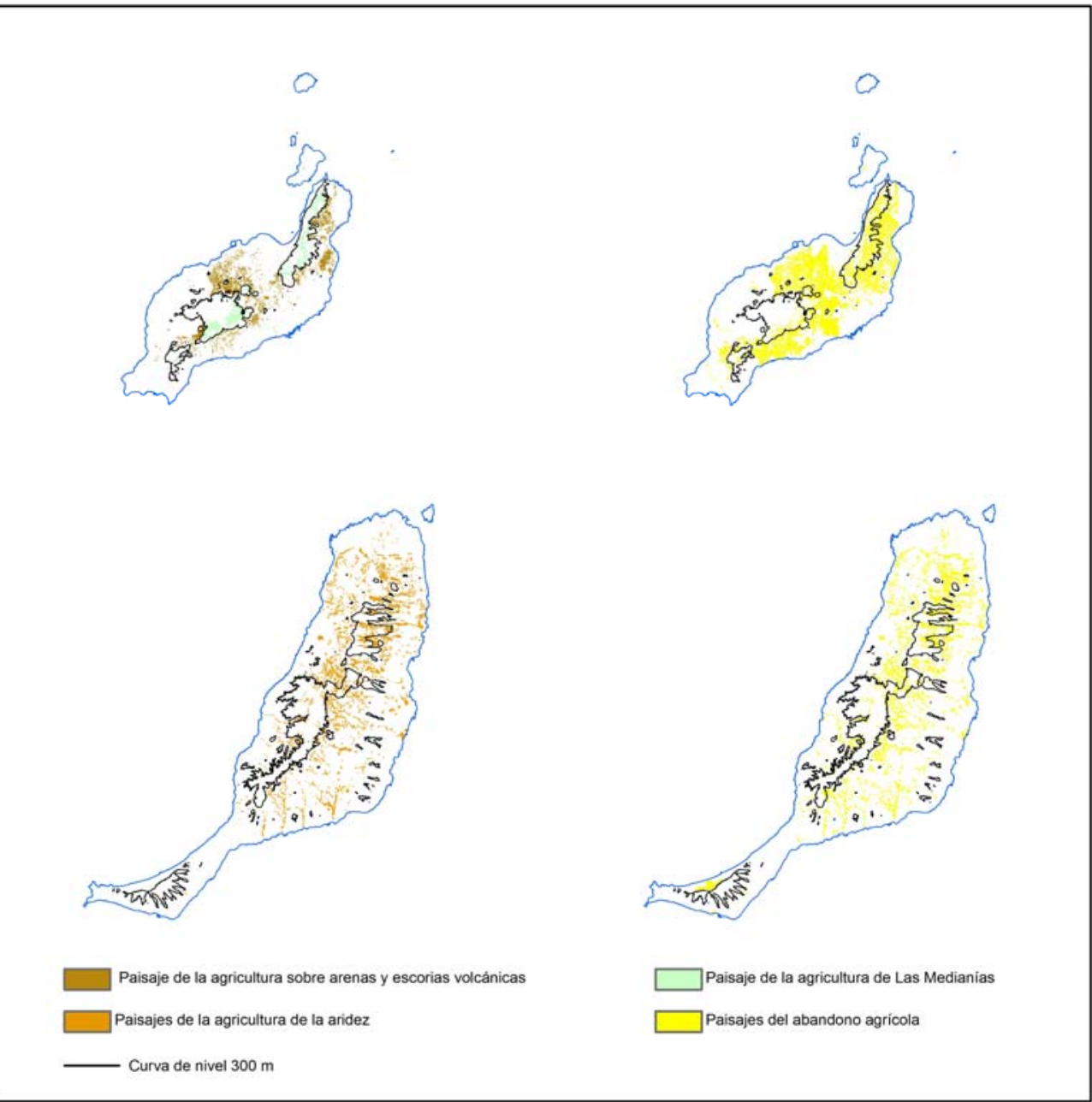

Fuente: Elaboración propia.

\subsection{LOS PAISAJES DE LA AGRICULTURA DE LAS MEDIANÍAS}

Este grupo variado de paisajes agrarios corresponde a la franja agroclimática de mejores condiciones topográficas, situada por encima de los $300 \mathrm{~m}$ o $400 \mathrm{~m}$ de altitud, en las islas de relieve, por lo que solo se insinúan levemente algunos de sus rasgos más característicos, como la humedad y la suavidad térmica, en las poco elevadas islas orientales, y por ello hemos denominado «protomedianías» al reducido piso superior existente en Lanzarote y Fuerteventura. Dicho elemento climático diferencial, 
derivado de la altitud y del flujo de los alisios, ha posibilitado el desarrollo de la agricultura tradicional de secano en esta importante franja actitudinal, basada en los principales cultivos mediterráneos y en algunos de origen atlántico, como cereales, leguminosas, vides y frutales, y el asentamiento semidisperso de la población, en un entorno más árido, representado por las zonas bajas. Estos elementos han servido para configurar una imagen tópica del espacio rural de las Islas, como un paisaje de pequeñas parcelas, huertas familiares, árboles frutales, casas de piedra con techo de teja, caminos empinados y barrancos profundos, que se considera en la actualidad como uno de los rasgos de la identidad paisajística de Canarias, a pesar del retroceso del policultivo de secano y de la urbanización de una parte de las parcelas abandonadas, por el método expedito de la autoconstrucción. Sin embargo, este amplio territorio, que posee más de la mitad de la superficie del Archipiélago, y está limitado en altura por los espacios naturales protegidos, y también por el monte en las islas occidentales, no es un todo homogéneo; sino que se trata de un conjunto discontinuo de cultivos, parcelas abandonadas, entidades de población, infraestructuras y espacios vacíos o cubiertos en algunos casos por la vegetación natural, que varía de unos lugares a otros de las islas en función de la orientación, de la altitud y disposición del relieve y de huella de la actividad humana presente y pretérita, ofreciendo diferentes caras en un espacio de reducidas dimensiones y elevado valor patrimonial.

Figura 14. Los enarenados han posibilitado una austera agricultura de secano en las áreas más áridas del Archipiélago. Valle de Haría, Lanzarote.

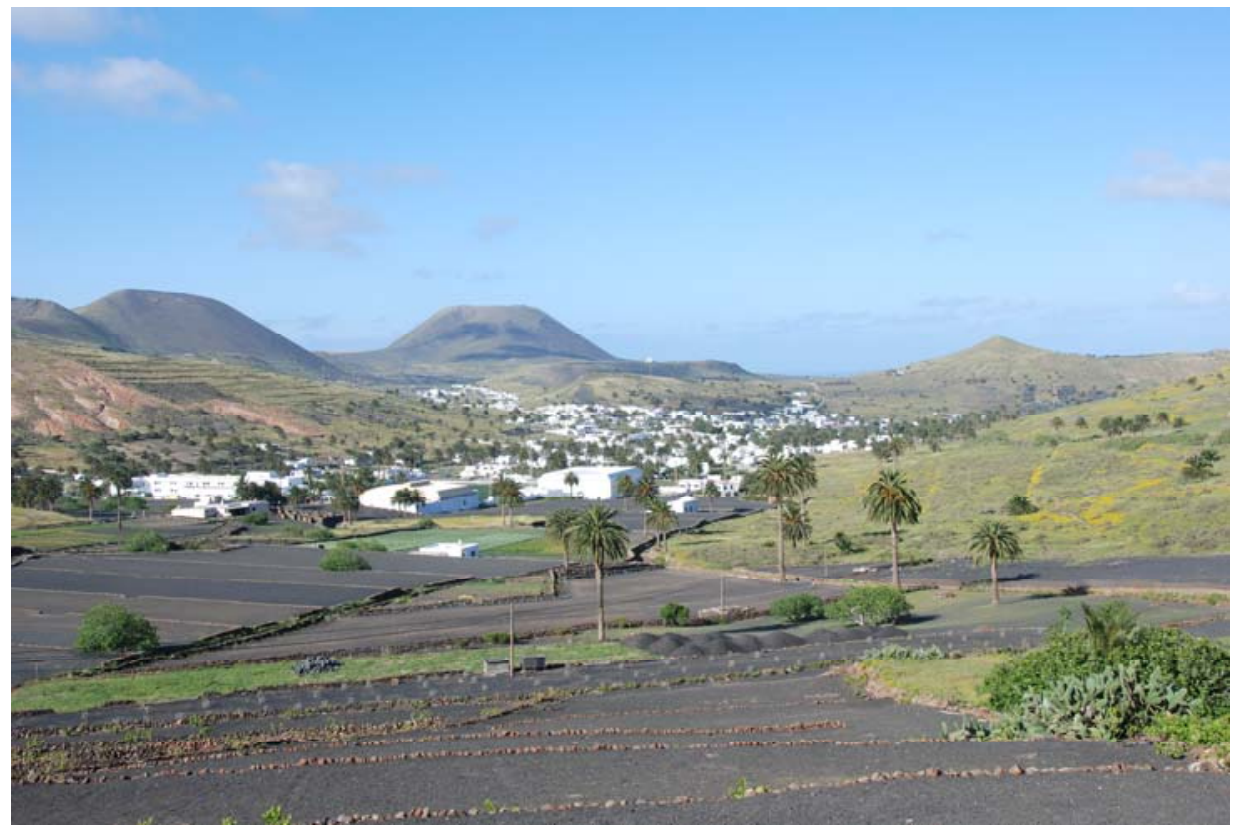

Fuente: Elaboración propia. 


\subsection{LOS PAISAJES DEL ABANDONO AGRÍCOLA}

Este conjunto de paisajes resultante del retroceso de la actividad agraria, en el último medio siglo en todos los ámbitos agroclimáticos del Archipiélago, es la modalidad de «ocupación» que más superficie registra en la región, en el presente, pues supera las 93.000 hectáreas, que es más del doble de la actual superficie cultivada, según los datos de la Estadística Agraria 2010, por lo que afecta nada menos que al 12,5 por ciento del territorio (figuras 11,12 y 13). En muchos sitios, las parcelas abandonadas aparecen junto a las explotaciones que se mantienen, especialmente en las áreas más húmedas de las Islas, dando lugar a un llamativo contrapunto entre actividad agrícola y atonía productiva, que en el pasado reciente ha supuesto el preludio de la autoconstrucción y de la urbanización en una amplia franja de Las Medianías. Pero en otros lugares las parcelas abandonadas son claramente dominantes, sobre todo en las vertientes meridionales de de las Islas, por lo que conforman una imagen más nítida del retroceso de la agricultura, en la que la caída de las paredes y la erosión van desdibujando los límites de los bancales y la colonización vegetal de las variedades más oportunistas acaba sepultando el antiguo paisaje agrario.

\section{CONCLUSIONES}

Las islas han sido consideradas desde el pasado como excelentes laboratorios para avance del conocimiento por su aislamiento, delimitación precisa, y dimensión abarcable por los investigadores, que han podido obtener datos específicos que han servido para aventurar hipótesis de trabajo que se han podido verificar después en territorios de mucha mayor extensión. Sin embargo, en algunos casos sucede justamente lo contrario, pues resulta difícil aplicar categorías de análisis espacial concebidas para territorios continentales o regionales a la escala insular, a causa de su modesta dimensión superficial y en muchos casos de su elevada fragmentación ocupacional. Esto ha ocurrido, por ejemplo, con las propuestas de tipificación de los paisajes de la agricultura de las Islas.

Por otra parte, la tierra cultivada en Canarias en la actualidad es muy escasa, pues abarca entre el 5,6 y 6,4 por ciento de la superficie regional, según la fuente oficial utilizada, repartiéndose en proporciones muy desiguales entre el secano y el regadío y también entre las diferentes Islas, en relación con su dimensión espacial y con la importancia relativa de la actividad agraria entre los usos y aprovechamientos insulares y el abandono de las explotaciones.

En este contexto de dispersión y baja densidad del espacio cultivado, el paisaje vinculado a las prácticas agrícolas más evidente en las Islas es precisamente el del abandono agrario, que supone el 12,5 por ciento de la superficie regional en los diferentes pisos de ocupación agraria, con sus parcelas vacías y sus paredes caídas, que van siendo invadidas por el matorral más oportunista o el bosque más colonizador, aunque a efectos estadísticos oficiales se considera todavía como un largo barbecho, 
carente de labores, y a la espera de ser cultivado en algún momento por unos agricultores inexistentes.

La limitación de la superficie cultivada, la dispersión de los cultivos, la escasa dimensión de las parcelas, debida a la inclinación del terrazgo y a la fragmentación histórica de la propiedad, y finalmente, la discontinuidad territorial de las explotaciones dificultan la clasificación específica de los diferentes tipos de paisajes vinculados a la actividad agraria, sobre unidades territoriales de suficiente dimensión espacial que las haga acreedoras de tal denominación conceptual y no la de simples variantes locales del mapa de cultivos.

La tipificación paisajística del espacio cultivado en Canarias ha sido abordada con anterioridad casi exclusivamente por dos autores, Álvarez Alonso (1993) y Martín Martín (2000), siguiendo metodologías aparentemente contrapuestas, a partir de planteamientos más agrarios que paisajísticos. El primero de los autores señalados establece una clasificación territorial de los paisajes con pocas unidades, basada en los conocidos pisos agroclimáticos, en los rasgos de aridez y humedad de los cultivos, e incluso en la finalidad de las explotaciones. En cambio, Víctor Martín propone una tipificación más amplia de los paisajes de la agricultura de las Islas, sustentada no solo en la diversidad de los cultivos y de las parcelas, sino también en los factores naturales y humanos de la agricultura, que se aproxima más en sus unidades a los sistemas de cultivo existentes en Canarias que a los paisajes de la agricultura propiamente dichos.

Por otra parte, la percepción popular ha distinguido siempre en las islas de relieve dos amplias zonas, el Norte y el Sur, utilizando como criterios de diferenciación las características climáticas específicas de cada vertiente, los rasgos paisajísticos y los principales elementos de uso de cada uno de dichos ámbitos insulares. Esta clasificación contrapone básicamente humedad y aridez, y simplifica los puntos cardinales en relación con sus posibilidades de explotación para el sistema agrario tradicional. Identifica el Norte con la zona húmeda de barlovento, afectada por la corriente del alisio, que sopla del noreste, genera abundante vegetación en las áreas más favorecidas; y ha posibilitado un mayor aprovechamiento agrario, y por tanto, una ocupación más intensa del territorio. Equipara el Sur con la vertiente de sotavento, que queda a cubierto de dicho flujo o está condicionada por los fenómenos orográficos de aceleración del alisio, y por lo tanto, resulta más árida y soleada, y en general, posee menos vegetación que la anterior, y asimismo presenta más dificultadas para el desarrollo de la agricultura de secano, especialmente por debajo de la curva de nivel de los $400 \mathrm{~m}$ de altitud.

Ambas fachadas insulares, separadas por el relieve de las montañas, han sido dos mundos muy diferentes en el modelo de desarrollo tradicional, por sus acusados contrastes en la distribución de los cultivos y de la población, a favor de la fachada septentrional. Estas diferencias socioeconómicas y demográficas se han ido suavizando en las últimas décadas, primeramente con la extensión de la agricultura comercial de regadío, en la zona baja, y posteriormente, con el desarrollo turístico. Ambas actividades han aprovechado las mejores condiciones térmicas y de insolación de la franja costera de la fachada meridional para la instalación de las explotaciones agra- 
rias y de las infraestructuras alojativas del turismo de masas, que han acabado compitiendo por el mismo espacio en algunos lugares de Tenerife y Gran Canaria.

En el Archipiélago canario, el destacado relieve de la mayor parte de las Islas ha dado lugar a la existencia de distintas franjas altitudinales en la ocupación del territorio, diferenciadas desde el pasado por la percepción de la población residente, que se basan en la presencia de factores naturales y humanos que han posibilitado una notable diversidad altimétrica de aprovechamientos y han generado una cierta variedad de paisajes rurales desde la zona baja hasta la cima de las montañas, en el modelo de desarrollo tradicional, pero que han llegado hasta nosotros, a pesar de los importantes cambios socioeconómicos que se han producido en el último medio siglo.

Para hacer referencia a los diferentes ámbitos altitudinales de uso y aprovechamiento, se han acuñado en el lenguaje ordinario de las Islas y en el vocabulario académico los conocidos términos de «costa», «medianías» y «cumbre», aplicados, respectivamente, a la zona baja, de características térmicas subtropicales, pero de escasas precipitaciones, e incluso de aridez, en muchos ámbitos meridionales de las islas de Tenerife y Gran Canaria; a la zona intermedia, altitudinalmente situada sobre la anterior, pero mucho más húmeda que esta, por el efecto combinado de los alisios y de la altitud, especialmente en la vertiente septentrional de las islas; y finalmente, la zona alta o de cumbre, localizada en la franja superior de la isla, en el ámbito del monte y del matorral de montaña media, con aprovechamientos fundamentalmente forestales y pastoriles, e incluida en alguna de las figuras de protección ambiental.

Finalmente, las consideraciones realizadas acerca de las dificultades inherentes a la tipificación de los paisajes de la agricultura de Canarias, planteadas en alguna medida por los autores pioneros en este tema a los que hemos hecho referencia, nos han llevado a cuestionar el papel exclusivo de los cultivos como elemento definidor de las unidades de clasificación paisajística del Archipiélago, teniendo en cuenta la fragmentación parcelaria y la dispersión del mapa de cultivos de la región; y a valorar la influencia de otros factores como los materiales usados como soporte de los cultivos, los sistemas agrarios existentes en las Islas, las técnicas de cultivo utilizadas en la diferentes áreas agrícolas del Archipiélago e incluso determinadas configuraciones culturales, a la hora de formalizar la propuesta de paisajes agrarios ofrecida en este trabajo.

\section{REFERENCIAS BIBLIOGRÁFICAS}

AFONSO PÉREZ, L. dir. (1984-1992): Geografía de Canarias. Editorial Interinsular Canaria, Santa Cruz de Tenerife.

ÁlVAREZ ALONSO, A. (1993): Los paisajes agrarios, Morales, G. ed., en Geografía de Canarias. Geografía General. Prensa Ibérica, Las Palmas de Gran Canaria, pp 309-324.

CÁCERES HERNÁNDEZ, J. J.; GUIRAO PÉREZ, G.; HERNÁNDEZ LÓPEZ, M.; MARTÍN ÁlVAREZ, F. J.; MARTÍN RODRÍGEUZ, G.; RODRÍGUEZ DONATE, M. C. (2004): Dimensión de la oferta vitivinícola en Canarias, V Jor- 
nadas Técnicas Vitivinícolas Canarias. Servicio Técnico de Agroindustrias e Infraestructura Rural, Cabildo Insular de Tenerife, $15 \mathrm{pp}$.

GARCÍA RODRÍGUEZ, J. L. y otros (1990): Atlas Interinsular de Canarias. Editorial Interinsular Canaria, Santa Cruz de Tenerife, pp.

GODENAU, D.; SUÁREZ SOSA, S. J. (2004): ¿Cuánto viñedo hay? Contraste de las diferentes fuentes estadísticas a través de una muestra de parcelas en la denominación de origen Tacoronte-Acentejo, V Jornadas Técnicas Vitivinícolas Canarias. Servicio Técnico de Agroindustrias e Infraestructura Rural, Cabildo Insular de Tenerife, $11 \mathrm{pp}$.

MARTÍN MARTÍN, V. O. (2000): Aproximación tipológica a los paisajes agrarios actuales de Canarias, Papeles de Geografía, 32, Universidad de Murcia, pp 97115.

VÁZQUEZ VARELA, C Y MARTÍNEZ NAVARRO, J. M. (2008). Del inventario patrimonial a la identificación de unidades de paisaje: estrategias en el marco de un desarrollo territorial sostenible, Diez Años de cambios en el mundo, en la Geografía y en las ciencias sociales, 1999-2008. Actas del X Coloquio internacional de Geocrítica. Universidad de Barcelona, 26-30 de mayo de 2008 (www.ub.edu/geocrit/-xcol/248.htm). 